NBER WORKING PAPER SERIES

COMMODITY TRADE MATTERS

Thibault Fally

James Sayre

Working Paper 24965

http://www.nber.org/papers/w24965

\author{
NATIONAL BUREAU OF ECONOMIC RESEARCH \\ 1050 Massachusetts Avenue \\ Cambridge, MA 02138 \\ August 2018
}

We would like to thank Dominick Bartelme, Justin Caron, Dave Donaldson, Ben Faber, Cecile Gaubert, Christophe Gouel, John Loeser, Dennis Novy, Gordon Rausser, Andres RodriguezClare, Sebastian Sotelo, Aaron Smith, Brian Wright and David Zilberman, as well as seminar participants at various venues for helpful comments and suggestions. We also thank May Lyn Cheah and Chengyao Sun for excellent research assistance. We gratefully acknowledge the financial support of the Giannini Foundation of Agricultural Economics for this project. The views expressed herein are those of the authors and do not necessarily reflect the views of the National Bureau of Economic Research.

NBER working papers are circulated for discussion and comment purposes. They have not been peer-reviewed or been subject to the review by the NBER Board of Directors that accompanies official NBER publications.

(C) 2018 by Thibault Fally and James Sayre. All rights reserved. Short sections of text, not to exceed two paragraphs, may be quoted without explicit permission provided that full credit, including (c) notice, is given to the source. 
Commodity Trade Matters

Thibault Fally and James Sayre

NBER Working Paper No. 24965

August 2018

JEL No. F10,O13

\begin{abstract}
$\underline{\text { ABSTRACT }}$
Primary commodities are used as inputs into all production processes, yet they account for approximately 16 percent of world trade. Despite their share in trade, we show that the aggregate gains from trade are largely understated if we ignore key features of commodities: low price elasticities of demand (difficulty in finding substitutes), low price elasticities of supply, and high dispersion of natural resources across countries. We develop a general-equilibrium model of consumption, production, and input-output linkages that explicitly accounts for these features. Our simulations confirm that the gains from trade are significantly larger, especially when considering large trade cost changes.
\end{abstract}

\title{
Thibault Fally
}

Department of Agricultural and Resource Economics

University of California, Berkeley

301 Giannini Hall

Berkeley, CA 94720-3310

and NBER

fally@berkeley.edu

James Sayre

Department of Agricultural and Resource Economics

University of California, Berkeley

207 Giannini Hall

Berkeley, CA 94720-3880

jsayre@berkeley.edu

An online appendix is available at http://www.nber.org/data-appendix/w24965 


\section{Introduction}

A continued concern associated with globalization is the access of countries to critical commodities in the world market. Pressing issues such as geopolitical instability combined with increased openness and a burgeoning demand for critical minerals used in new technologies have made understanding the role of international commodity trade even more important today. Quantifying the interdependency of nations on trade in natural resources has crucial implications for international relationships, such as the risk countries face due to instability in access to global markets, as well as how much countries would lose by imposing barriers to trade, such as the creation of tariffs on imported commodities or by cutting off a key trading partner.

Despite recognition among academics of the importance of international trade, several recent papers have found that the welfare gains from international trade are modest: using a formula proposed by Arkolakis et al. (2012) that applies to a wide range of models, estimates of the gains from trade equal $1.4 \%$ of GDP for the US in $2000 .{ }^{1}$ These models, however, make stark assumptions that do not fit stylized facts about most primary commodities. Commodities are characterized by several traits, which include: low responsiveness of both demand and supply to changes in price, reliance on natural resources, and a high concentration of these natural resources among only a few countries (e.g. Chile for copper, South Africa for platinum, Congo for cobalt). As shown in previous work (see Gilbert 2010, Wright 2011), these features can explain the high volatility of the price of these commodities. But little research has yet been undertaken to examine the implications of these features for the quantification of the gains from trade.

The idea motivating this paper can be simply illustrated using a textbook two-commodity diagram for the gains from trade, as shown in Figure 1. Conditional on the same values of observed production $E$ and consumption $C$, the gains from trade depend upon the shapes of the isoquant ${ }^{2}$ and the production possibility frontier (PPF). In the left panel (a), demand and production can adjust flexibly to changes in relative prices, whereas in the right panel (b), both the isoquant and PPF are more convex (inelastic). We argue that trade with commodities corresponds to the case of inelastic supply and demand, where the gains from trade are the largest. Furthermore, as commodity production tends to be concentrated among few countries, this leads to larger differences between demand $C$ and production $E$, and thus larger implied gains from trade.

We embed such channels and quantify the gains from trade in an otherwise standard model with gravity equations for international trade in each final good and primary commodity. To do so, we proceed in three steps. First, we assemble a rich dataset on trade, production, and prices across 169 detailed commodities with which we document several stylized facts on trade in primary com-

1. Given an import penetration of $7 \%$ and an elasticity of trade to trade costs equal to 5 .

2. Combinations of commodities that yield the same quantity $Y$ of final good output. 
Figure 1: Elasticity of substitution, convexity and gains from trade

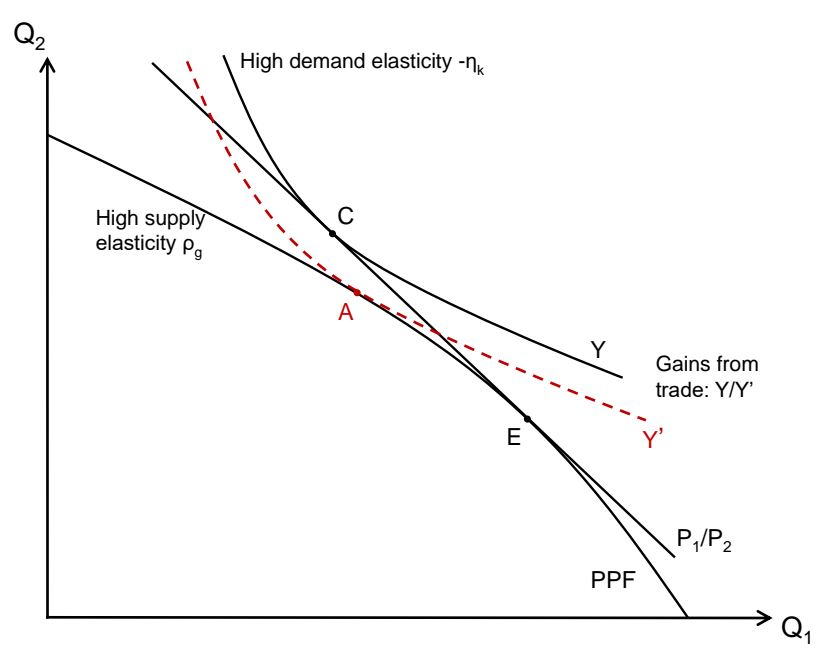

(a) High elasticity of substitution

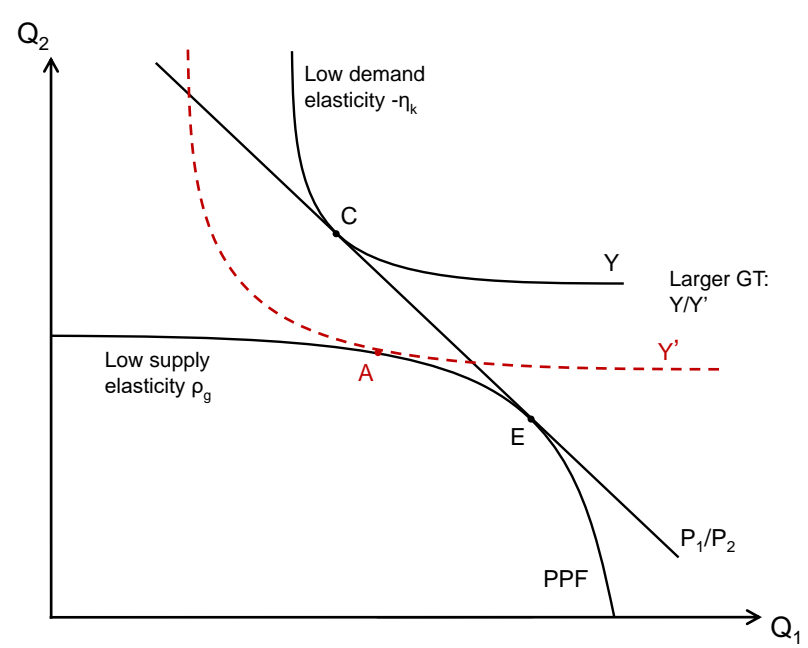

(b) Low elasticity of substitution

modities. Next, we develop a general-equilibrium model of trade that accounts for these specific features and stylized facts. Finally, we use our model and data to simulate counterfactual equilibria with higher trade barriers and confirm that ignoring these specific features of commodities leads to a wide understatement of the gains from trade.

In order to assess the gains from trade, an essential step is to assemble and harmonize trade and production data at a disaggregated level. ${ }^{3}$ Current datasets of trade and production generally aggregate commodities into broad categories, such as "minerals". This level of aggregation is not able to account for the input-output linkages found in commodity trade. For instance, although many countries produce mineral commodities broadly, the production of specific minerals is highly dispersed across countries. To capture this level of granularity, we use detailed data on production in order to match the trade data available across 6-digit or 4-digit HS product categories. As there is no readily-available dataset at a such a disaggregated level spanning many commodities, production and price data are gathered from various sources. ${ }^{4}$ We then document several stylized facts that describe trade in commodities: the concentration of trade and income in a few commodities and countries, the low elasticities of supply and demand from our own meta-analysis covering many scattered sources, and the responsiveness of trade in commodities to trade barriers. These features help justify the assumptions of our model and explain the large gains from trade in commodities.

Our model includes multiple (traded) sectors, two stages of production (final goods and commodities) and different factors of production (labor and natural resources). ${ }^{5}$ The production of

3. Our harmonized production and trade data are provided here: http://are.berkeley.edu/ fally/data.html

4. For downstream industries, we employ data from the World Bank and GTAP at a more aggregate level. We also combine this with commodity use by downstream industry across finely-defined commodities.

5. In our model, "labor" refers to a factor of production that is mobile across sectors. We do not explicitly differ- 
final goods relies on labor and commodities, while the production of commodities relies on labor and natural resources. We depart from an otherwise standard model of trade (a multi-sector Eaton and Kortum 2002 framework) in several ways in order to account for trade in scarce commodities. First, on the supply side, the production of commodities requires a mobile factor, labor, and a specific factor, natural resources, with potentially low elasticities of substitution between them. We assume that each commodity requires a given natural resource, such as copper deposits for copper production or a certain bundle of climatic and agronomic characteristics for agricultural products. An unequal distribution of these resources can then explain why the production of some commodities is highly concentrated across space. Furthermore, a low elasticity of substitution between inputs combined with the presence of a fixed factor generates a low price elasticity of supply, as typically observed for commodities. In turn, we assume that final good production requires both labor and commodities, allowing for a potentially low elasticity of substitution in order to generate a low price elasticity of demand for commodities. While commodities account for a small share of total costs in downstream sectors, those commodities would be very costly to replace if their supply was cut off.

The model can be calibrated using estimates of several key parameters such as supply, demand and trade elasticities, as well as moments that can be observed in the data, such as production, trade flows and input-output relationships. Our calibrated demand and supply elasticities are well below unity, but remain conservative relative to most estimates of both short and long-run elasticities. In a few specific cases, we provide closed-form solutions for the gains from trade to generalize Arkolakis et al. (2012) with commodity trade and highlight the role of substitution and trade elasticities, as well as the patterns of production in the baseline equilibrium.

We consider several counterfactuals to illustrate the role that commodities play in trade. Comparing the baseline equilibrium to autarky, we find vastly larger changes in welfare compared to models with only one factor of production or higher elasticities of substitution. For large countries such as the United States, gains from international trade double. For the median country, gains from trade are three times larger than in standard models. For small countries with few resources, the gains from trade are enormous. We find that the gains from trade are much more (negatively) correlated with market size if we account for natural resources and trade in commodities. Mobile factors of production (workers) tend to gain more from trade than the country on aggregate, while the gains from trade across owners of natural resources are highly heterogeneous.

These results are greatly muted if we consider higher elasticities of substitution between natural resources and labor in the production of commodities, or between commodities and labor in downstream industries. Gains from trade are less dispersed for natural resource owners when elasticities of substitution are higher. In contrast, considering a higher (quadruple) elasticity of trade entiate labor from capital. A distinction between labor and capital would not play an important role. 
for commodities only moderately erodes the gains from trade and the distribution of the gains, unlike the formulas in Arkolakis et al. (2012).

We also examine intermediate trade cost changes and tariffs. With commodities, the gains from trade are highly non-linear - effects of trade cost changes are much larger as the economy approaches autarky - but the difference with benchmark models without commodities or natural resources is non-negligible even further away from autarky. Interestingly, tariffs generate only tiny differences from the benchmark model given that the deadweight loss is small with low elasticities of commodity demand and supply. Finally, we illustrate the role of critical suppliers in each commodity by simulating the effect of cutting off from trade the top export of each commodity on prices in other countries for that commodity. We find large effects on prices, mainly driven by the increase in production costs due to the increase in supply from other countries (combined with low price elasticities of supply). In particular, we examine the substantial role of China as a major supplier of many commodities and its influence on world prices and US prices.

Literature Our paper is unique in examining the implications of the aforementioned specific features of many primary commodities for the quantification of the gains from trade. That said, our work draws from a large literature regarding commodities, and our model and calibration approach is similar to a number of other recent papers aimed at quantifying the effect of trade costs and trade policy changes on various economic outcomes.

On the theoretical side, our work relates to three subgroups of papers that examine the gains from trade with: i) input-output links between industries (Alexander 2017, Antràs and Gortari 2017, Caliendo and Parro 2015, Costinot and Rodríguez-Clare 2014), ii) gains from trade with multiple factors of production (Galle et al. 2017, Burstein et al. 2018), and iii) gains from trade from the specialization of land and natural resources in exported products (Costinot and Donaldson 2016, Farrokhi 2018, Sotelo 2017). We depart from the literature on multi-stage production by assuming a key role for natural resources that are unevenly allocated across countries, and difficult to substitute. These features generate much larger gains from trade than typical models with multiple stages of production. Our approach is close to multi-factor models, although we consider many more factors of production (natural resources are specific to each commodity) and lower demand and supply elasticities than usually assumed for instance across different types of labor (Galle et al. 2017, Acemoglu 2002). Perhaps closest to our work is Farrokhi (2018), who develops a general-equilibrium model to incorporate how changes in oil production affect downstream demand and trade flows, arguing that the gains from trade in a model considering oil are larger than more general, existing models. Our underlying mechanism is also reminiscent of Ossa (2015), who finds absolute gains from trade that are several times larger after accounting for the heterogeneity in trade elasticities across industries. In our framework, commodities largely contribute 
to the gains from trade because of low supply and demand elasticities, in spite of similar, or even potentially higher, trade elasticities. ${ }^{6}$

More broadly, our paper relates to recent work examining the pecularities and importance of agricultural commodities in trade. Gouel and Laborde (2017) show that by incorporating a lower elasticity of demand and supply in a model of agricultural trade, the expected welfare losses due to climate change increase, particularly harming countries in Sub-Saharan Africa. Further, Heerman and Sheldon (2018) argue that given systematic correlation in agricultural productivities across countries and patterns of specialization in crop production, the assumptions inherent in the standard gravity form of trade flow patterns must be relaxed. As patterns of specialization differ widely across the types of agricultural products and countries, such patterns present a strong argument for a highly granular treatment of agriculture trade. ${ }^{7}$

Our calibration method draws from recent work such as Dekle et al. (2008) and Caliendo and Parro (2015), as well as the Computational General Equilibrium (CGE) modeling literature discussed by Hertel et al. (1992). With this approach, trade shares, production shares and key elasticities are sufficient to solve for counterfactual changes in general equilibrium, without approximations ("exact hat algebra"). For instance, Caliendo and Parro (2015) apply these techniques to examine the effect of NAFTA on production and employment and Caron and Fally (2017) examine the effects of changes in income and consumption on $\mathrm{CO} 2$ emissions in a general equilibrium framework with trade.

Finally, our work relates to a vast literature focusing on the consequences of commodity production, particularly developing countries where production is highly concentrated in only a few products. Such consequences include sectoral shifts away from other industries towards commodity production in the wake of large resource discoveries (Corden and Neary 1982), as well as slower observed rates of growth for resource rich countries (Sachs and Warner 1999). With a large dependence on commodity production, commodity price shocks can play a large (potentially adverse) role in development. Blattman et al. (2007) show that developing countries that export commodities with higher price volatility have lower growth rates. Similarly, Drechsel and Tenreyro (2017) show that commodity prices have been a large driver of growth for developing countries, arguing that commodity price shocks account for about $38 \%$ of fluctuations in post-1950 growth in Argentina. Recent work has also examined whether natural resource discoveries increase or decrease foreign direct investment across resource and nonresource sectors (Toews and Vézina 2017, Poelhekke and Ploeg 2013). ${ }^{8}$

6. Trade elasticities used by Ossa (2015) are not significantly different between primary commodities and other goods. Moreover, with low elasticities of supply and demand, we find that large increases in the trade elasticity have relatively muted effects relative to standard models.

7. We examine agricultural production and trade at disaggregated level, examining specific products, rather than simply "agriculture" or "grains", for example.

8. Our analysis of the importance of commodity trade also relates to the literature on commodity price movements 
The remainder of the paper proceeds as follows; the second section describes the data and documents several stylized facts. The third section develops the model and theoretical findings. The fourth section documents the calibration of the baseline model. The fifth section examines counterfactual equilibria using our calibrated model to illustrate the gains from trade with commodities. The sixth section concludes.

\section{Data and stylized facts}

\subsection{Data sources}

We draw from a varied set of data sources for information on production, prices, trade, and inputoutput linkages across commodities. In an online appendix, we provide additional information on the construction of our dataset, in addition to providing our data online. ${ }^{9}$

Production data. For minerals, the main source of production data is the British Geological Survey (2015), which provides mineral production data at the country level from 1913 to 2015. For agriculture, the main source of agricultural data is from the Food and Agriculture Organization of the United Nations (2017) (FAO), which provides data from 1960 to 2014 on the production of agricultural products at the country level. Supplementally, we employ production data from the Global Trade Analysis Project, or GTAP (Aguiar et al. 2012) for downstream industries in the year 2007.

Trade data. For information on trade flows, we employ BACI data, constructed by CEPII and based on UN-Comtrade data (Gaulier and Zignago 2010). These data are detailed at the 6-digit level of the Harmonized Commodity Description and Coding System (HS), of which we use the 1992 nomenclature. In order to match production and trade data, we further aggregate the trade data to match the level of granularity in the production data. These cover the years 1995 to 2014.

Price data. We use the United States Geological Survey Historical Statistics for Mineral and Material Commodities in the United States for prices of mineral commodities (Kelly and Matos

and commodity price booms and busts, which is reviewed by Carter et al. (2011) and Radetzki and Wårell (2017). Williams and Wright (2005) and Cafiero et al. (2011) show that the competitive rational storage model, coupled with a sufficiently low elasticity of demand, can rationalize the high volatility of commodity prices. Additionally, Jacks and Stuermer (2018) decompose commodity price booms and busts from 1870-2013 and conclude that most price shocks are driven by changes in demand, rather than supply shocks. Similarly, Gilbert (2010) argues that one of the main reasons for price booms is the low responsiveness of agricultural production to sudden demand shocks that are correlated across agricultural commodities.

9. http://are.berkeley.edu/ fally/data.html 
2014). This is the most comprehensive source of yearly price data for minerals, however it does not cover mineral prices for countries other than the US. We complement this price data with the IMF Primary Commodity Price Series database for uranium prices (Commodities Team of the Research Department, IMF 2017), the World Bank Commodity "Pink Sheets" for fuel petroleum and coal prices (World Bank Group 2017), and U.S. Energy Information Association (2017) data on natural gas prices. For agricultural products, we use producer price data from the FAO at the country level when available, and use median world agricultural prices for commodities when country level prices are unavailable or unrealistic (for more information, see Appendix Section 6).

Commodity end use. A few sources report figures for commodity consumption by downstream sectors. GTAP data provide end use information between several categories of primary commodities $^{10}$ and broad secondary and tertiary industrial sectors, which we use for agricultural commodities and fuel products. However, mineral commodities are more highly aggregated by the GTAP classification (grouped into only two categories), despite their relatively complex downstream usage compared to agricultural commodities. To rectify this, we employ USGS end usage data (Barry et al. 2015) for each mineral commodity across downstream NAICS industry codes at the 3 or 6digit level. Where possible, we match each NAICS code to the GTAP classification coding system to determine the relative use of a given mineral by each downstream GTAP industrial sector.

\subsection{Stylized facts}

Before turning to the setup of our model, we document a series of stylized facts on the specific patterns of commodity trade to motivate the key assumptions of the model and help explain the large gains from trade in commodities.

Fact 1: Commodities account for a modest share of world trade. As a percentage of total trade, commodities account for a modest share, approximately 16 percent of the value of world trade in 2014 (following the BEC classification). However, this share has not been constant over time. Figure 2 and Appendix Table 10 exhibit the trends in commodity trade both from the period of 1962 to 1995 (panel a) and from 1995 to 2014 (panel b). We find that the share of world trade in all commodities has experienced a decline since 1962, but has leveled off from the period of 1995 to 2014. Recently, the share of fuels has increased, making up for some of the decline of commodities in world trade. Our study examines some directly-related intermediate products at a slightly more processed level, e.g. we include smelted copper as well as copper ore in our baseline calibration (see Appendix E for the list of primary commodities in our study). Including those

10. Aggregated into 15 categories (excluding cattle), leaving fuels and most agricultural commodities at a fine level. 
intermediate products, the share of commodities is about 3\% higher and has the same variation across years. Hence, the products in our study (the first three columns of Table 10) encompass a slightly larger share of world trade, up to 20 percent of world trade in 2014 and 18 percent on average.

Figure 2: Evolution of the share of primary commodities in world trade

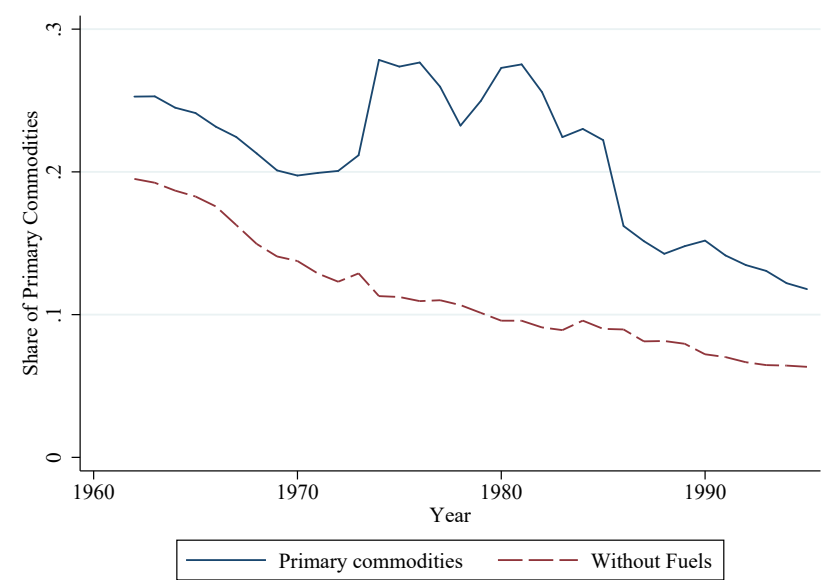

(a) 1962-1995 (Feenstra data)

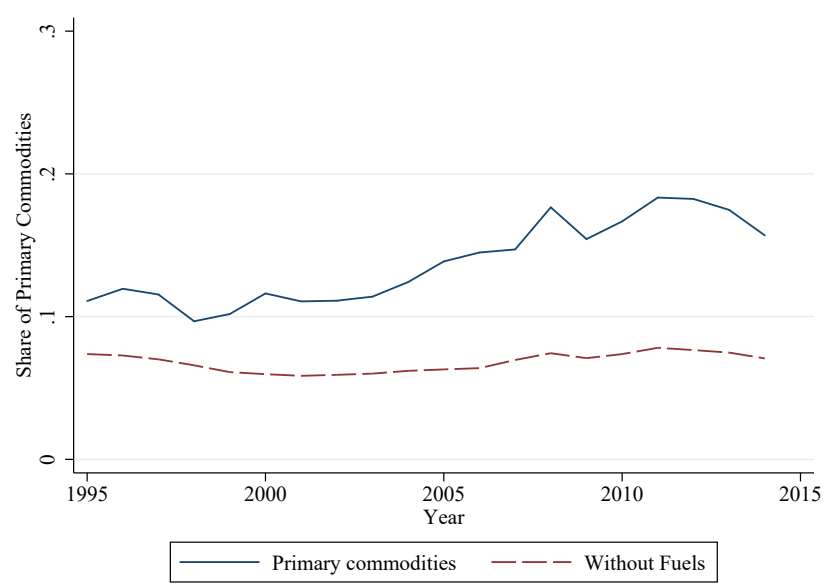

(b) $1995-2014$ (BACI data)

Fact 2: Commodities face low supply and demand elasticities. We conduct a meta-analysis of price elasticity estimates in the literature over the past decades. Since price elasticities matter greatly for examining the patterns of commodity prices, production, and consumption, hundreds of papers have estimated price or income elasticities for commodities, often with an emphasis on price elasticities of demand.

Due to the importance of commodity elasticity estimates in a wide variety of domains, several studies and sources have compiled reviews of elasticity estimates in the literature. Examples include Muhammad et al. (2011), who review price elasticity estimates of supply and demand for numerous agricultural commodities, Jenkins (2011), who reviews estimates for 17 commodities produced in Latin America (4 minerals, oil and 12 agricultural products), and Caldara et al. (2016), who compile elasticity estimates for oil. For other commodities, especially minerals, we need to gather elasticity estimates from scattered and diverse sources. Examples are Roberts and Schlenker (2013) for 4 agricultural commodities, Stuermer (2017) on demand for 5 minerals over more than a century, Gupta and Gupta (1983) for short and long run demand for cobalt, Blomberg and Hellmer (2000) for supply and demand of aluminum, and Coyle et al. (2012) for crude oil.

We refer to Table 6 in the Appendix for the current list of papers that we have surveyed in addition to the estimates covered in these surveys. This review is not intended to be exhaustive, 
Table 1: Selected estimates of supply and demand elasticities for commodities

\begin{tabular}{|c|c|c|c|c|c|}
\hline Commodity & $\begin{array}{c}\text { Price Elasticity } \\
\text { of Demand }\end{array}$ & $\begin{array}{c}\text { Price Elasticity } \\
\text { of Supply }\end{array}$ & Commodity & $\begin{array}{c}\text { Price Elasticity } \\
\text { of Demand }\end{array}$ & $\begin{array}{c}\text { Price Elasticity } \\
\text { of Supply }\end{array}$ \\
\hline Alfalfa & -0.107 & 0.44 & Niobium & $(-0.295$ to -0.3$)$ & \\
\hline Almonds & $(-0.35$ to -0.48$)$ & 0.19 & Palladium & -0.2 & \\
\hline Aluminium & $(-0.07$ to -0.7$)$ & (0.05 to 1.15$)$ & Peanuts & $(0.0$ to -0.4$)$ & $(0.04$ to 0.5$)$ \\
\hline Bananas & $(-0.566$ to -0.738$)$ & $(0.2$ to 0.4$)$ & Petroleum & $(-0.034$ to -0.44$)$ & \\
\hline Barley & $(-0.11$ to -0.435$)$ & $(0.11$ to 0.45$)$ & Platinum & $(-0.28$ to -0.7$)$ & \\
\hline Chromium & $(-0.1$ to -0.277$)$ & & Pulse grains & $(-0.339$ to -0.71$)$ & 0.17 \\
\hline Citrus & $(-0.804$ to -0.994$)$ & & Rice & $(0.007$ to -0.55$)$ & (0.01 to 0.57$)$ \\
\hline Coal & $(-0.3$ to -0.7$)$ & 0.057 & Roots & $(-0.635$ to -0.737$)$ & \\
\hline Cobalt & $(-0.029$ to -0.5$)$ & $(0.21$ to 1.0$)$ & Silver & -0.042 & \\
\hline Cocoa & $(-0.01$ to -0.14$)$ & (0.03 to 0.12$)$ & Sorghum & $(-0.06$ to -0.49$)$ & $(0.16$ to 0.53$)$ \\
\hline Coffee & $(-0.07$ to -0.54$)$ & $(0.02$ to 0.55$)$ & Soybeans & $(-0.05$ to -0.329$)$ & $(0.061$ to 0.705$)$ \\
\hline Copper & $(-0.035$ to -0.42$)$ & $(0.06$ to 1.2$)$ & Sugar & $(-0.01$ to -0.643$)$ & $(0.055$ to 0.21$)$ \\
\hline Corn & $(-0.1$ to -0.39$)$ & $(0.08$ to 0.7$)$ & Sunflower & $(-0.083$ to -0.15$)$ & $(0.15$ to 0.41$)$ \\
\hline Cotton & -0.684 & 0.497 & Tin & $(-0.097$ to -0.55$)$ & $(0.032$ to 1.11$)$ \\
\hline Crude Oil & $(-0.003$ to -0.08$)$ & (0.0 to 0.289$)$ & Titanium & -0.16 & \\
\hline Gold & -0.411 & & Tomatoes & $(-0.32$ to -0.723$)$ & 0.27 \\
\hline Iron & -0.086 & 0.589 & Tungsten & $(-0.15$ to -0.5$)$ & (0.11 to 0.15$)$ \\
\hline Lead & $(-0.111$ to -0.22$)$ & (0.109 to 1.84$)$ & Uranium & & (1.1 to 11.4$)$ \\
\hline Manganese & -0.1 & $>1.0$ & Vanadium & $(-0.254$ to -0.3$)$ & \\
\hline Mercury & -0.1 & 1.0 & Walnuts & $(-0.251$ to -0.267$)$ & 0.02 \\
\hline Natural Gas & $(-0.053$ to -0.95$)$ & $(0.0$ to 0.15$)$ & Wheat & $(-0.09$ to -1.6$)$ & $(0.059$ to 0.43$)$ \\
\hline Nickel & -0.038 & (0.133 to 2.03$)$ & Zinc & $(-0.064$ to -0.47$)$ & $(0.085$ to 1.75$)$ \\
\hline
\end{tabular}

Notes: The full lists of estimates and references are provided in Appendix Table 6. The parentheses indicate the ranges of estimates when more than one estimate is available, or when the author only offers an estimate of the range.

especially for elasticity estimates of agricultural and fuel commodities, but we have attempted to review recent mineral elasticity estimates comprehensively, as they correspond to a smaller literature. Further, Table 1 provides summary statistics for these elasticity estimates; in cases where there are multiple estimates, we provide a range of elasticities.

Appendix Figures 14(a) and 14(b) plot the empirical distributions of the elasticity estimates we have surveyed. Most estimates fall within the 0.1 and 0.5 range (in absolute value), both on the supply side and demand side. The modal estimate for both distributions appears to be somewhat less than 0.2 (in absolute value); assuming demand and supply elasticities of 0.4-0.6, as we do in our simulations in Section 4, is quite conservative ${ }^{11}$. The majority of these estimates are short to medium-run elasticities, i.e. examining supply and demand responses within a year. Several papers also estimate long-run elasticities for commodities (see Appendix Table 6), which leads to slightly

11. Papers such as Roberts and Schlenker (2013) have argued that "naive" estimates of supply and demand elasticities for storable commodities are biased to zero due to the role of futures prices and anticipated shifts in supply. Still, using past yield shocks as instruments, the authors' own estimates of supply and demand estimates for four commodities/commodity groups are rarely larger than 0.4 in absolute value. 
higher elasticities, but these figures still remain low. ${ }^{1213}$ In comparison, most estimates of the elasticity of substitution between skilled and unskilled workers lie between 1.4 and 2 (Acemoglu 2002, Autor et al. 1998), with a few exceptions as low as 1 and as high as 4.

Fact 3: Commodity prices are volatile. As part of the consequences of low demand and supply elasticities, the fluctuations in commodity prices can be quite large. Table 2 presents historical price volatility of commodities, broken down by agriculture, fuels, and minerals. We measure volatility as the standard deviation of log price changes (rather than the standard deviation of log prices, the latter being less robust to small trends). On average, the yearly volatility of commodity prices is around $20 \%$. Over a longer term horizon, price fluctuations can also be large and cumulative, since many commodities have price evolution patterns with very low mean reversion (Cashin et al. 2000, Cohen et al. 2006). The consequences of this volatility can be large, especially for exporters and importers for whom a commodity represents a large share of trade (see Fact 8). Further, Jacks et al. (2011) present centuries of evidence indicating that commodity prices have long been more volatile than the prices of manufactured goods.

Table 2: Commodity Price Volatility, 1975-2014

\begin{tabular}{l|ccc}
\hline \hline & Agriculture & Minerals & Fuels \\
\hline 1975 to 1984 & 0.300 & 0.209 & 0.209 \\
1985 to 1994 & 0.361 & 0.173 & 0.168 \\
1995 to 2004 & 0.178 & 0.213 & 0.258 \\
2005 to 2014 & 0.154 & 0.262 & 0.322 \\
All years & 0.295 & 0.226 & 0.271 \\
\hline
\end{tabular}

Source: Price data from the FAO, IMF, World Bank, EIA, and USGS. Volatility is defined as the standard deviation of yearly changes in log prices, averaged across commodities within a group.

Fact 4: Trade elasticities are not significantly higher for commodities. Table 3 reports the results of our estimations of gravity equations for the products in our sample. Gravity equations are estimated separately for each commodity with the Poisson-PML estimator, including exporter and importer fixed effects to account for multilateral resistance terms (e.g. as in Fally 2015 among

12. For example, Stuermer (2017) estimates long run demand elasticities for 5 minerals using a data set back to 1840 , finding elasticities of around -0.2 for lead, tin, and zinc, -0.4 for copper, and -0.7 for aluminum. With the inclusion of country fixed effects, downstream industry output, and potentially time trends, these estimates seem to correspond closely to our parameter $\eta_{k}$. Similarly, Gupta and Gupta (1983) estimate long run demand for superalloyed Cobalt (roughly the level of refinement that would be demanded by downstream industries) and finds a price elasticity of -0.46 , including downstream production controls.

13. Scott (2014) argues that static analyses of long-run supply elasticities may generate lower elasticity estimates, although a dynamic model incorporating crop choice suggests that overall crop supply has an elasticity around 0.3. 
Table 3: Gravity equation and trade cost coefficients across commodities

\begin{tabular}{|c|c|c|c|c|c|c|}
\hline \multirow[t]{2}{*}{ Dependent var.: } & \multicolumn{5}{|c|}{ Trade flows } & \multirow[b]{2}{*}{$(6)$} \\
\hline & (1) & (2) & (3) & (4) & (5) & \\
\hline Industry & $\begin{array}{l}\text { Aggregate } \\
\text { trade }\end{array}$ & $\begin{array}{l}\text { GTAP } \\
\text { sectors }\end{array}$ & $\begin{array}{c}\text { All } \\
\text { commodities }\end{array}$ & $\begin{array}{l}\text { Agriculture } \\
\text { only }\end{array}$ & $\begin{array}{l}\text { Fuel } \\
\text { only }\end{array}$ & $\begin{array}{c}\text { Minerals } \\
\text { only }\end{array}$ \\
\hline \multirow[t]{2}{*}{ Distance (log) } & -0.818 & -0.972 & -1.479 & -1.662 & -2.432 & -1.148 \\
\hline & {$[0.072]$} & $(0.201)$ & (1.003) & $(0.94)$ & $(0.814)$ & (1.004) \\
\hline \multirow[t]{2}{*}{ Border effect } & -2.740 & -1.965 & -3.570 & -3.630 & -2.417 & -3.531 \\
\hline & {$[0.218]$} & $(0.683)$ & $(3.833)$ & $(2.76)$ & $(0.834)$ & $(5.13)$ \\
\hline \multirow[t]{2}{*}{ Contiguity } & 0.404 & 0.425 & 0.081 & 0.326 & 0.491 & -0.320 \\
\hline & {$[0.120]$} & $(0.169)$ & $(4.234)$ & (1.329) & $(0.662)$ & $(6.612)$ \\
\hline \multirow[t]{2}{*}{ Common Language } & 0.502 & 0.403 & 0.316 & 0.544 & 0.526 & -0.050 \\
\hline & [0.146] & $(0.181)$ & $(1.146)$ & $(0.904)$ & $(0.268)$ & (1.39) \\
\hline \multirow[t]{2}{*}{ Colonial Link } & 0.036 & 0.248 & 0.624 & 0.150 & 0.461 & 1.373 \\
\hline & {$[0.146]$} & $(0.24)$ & $(5.974)$ & $(0.947)$ & $(0.362)$ & $(9.53)$ \\
\hline In brackets: & Std Errors & Std. Dev. & Std. Dev. & Std. Dev. & Std. Dev. & Std. Dev. \\
\hline Countries & 94 & 109 & 143 & 143 & 143 & 143 \\
\hline Commodities & l & 18 & 167 & 100 & 3 & 64 \\
\hline
\end{tabular}

Notes: PPML with fixed effects by importer and exporter; robust standard errors in brackets. First column is from Fally (2015). Column (2) reports averages of coefficient estimates across GTAP manufacturing industries (codes 25-42). Columns (3)-(6) report averages of coefficient estimates across gravity equations for separate commodities (167 separate commodities in column (3), less for columns (4)-(6)). The numbers in parentheses reported below the coefficient estimates for columns (2)-(6) are the standard deviations of the coefficient estimates, not standard errors.

many others). Table 3 column (1) is estimated using aggregate trade flows and reports the coefficient for each trade proxy and its estimated standard error. Column (2) reports the average and standard deviation of gravity equation coefficients across GTAP manufacturing sectors (codes 2542). Columns (3) to (6) report the average of the coefficients for each trade proxy as well as the the standard deviation of these coefficients across commodities within each broad categories (in parentheses).

Primary commodities do not seem to have starkly higher distance elasticities than trade on aggregate or across manufacturing sectors in GTAP. However, there is some heterogeneity in these estimates, as shown by the standard deviations of the coefficients. Additionally, some commodities seem to have higher distance elasticities than others, for instance trade is more elastic for fuels than for minerals with respect to distance.

Also crucial is the elasticity of trade with respect to trade costs and tariffs, which differs from the distance elasticity documented above (the distance coefficient is the product of the elasticity of trade to trade costs, which we will call $\theta$ in Section 3, and the elasticity of trade costs to each of the trade cost proxies). Several papers have estimated these elasticities for primary commodities vs. other sectors (Arkolakis et al. 2013, Broda and Weinstein 2006, Caliendo and Parro 2015, 
Donaldson 2018, Farrokhi 2018, Ossa 2015, Sotelo 2017, and Tombe 2015) and generally find that trade elasticities for commodities are not larger than for other industries. For instance, Tombe (2015) estimates that $\theta$ equals 4.63 for manufacturing and 4.06 for agriculture. Caliendo and Parro (2015), however, find higher elasticities for mining and petroleum than most other industries, focusing on trade in North America. In our baseline calibration, we assume that the trade elasticity is the same across all sectors and examine the robustness of our results to this assumption by quadrupling the trade elasticity for primary commodities only.

\section{Fact 5: Commodities tend to be upstream and purchased by a few specific downstream sec-}

tors. In the 2007 US input-output tables, defined across 6-digit NAICS commodity and industry categories (about 430 sectors), we find that the top purchasing industry accounts for $35 \%$ of total purchases of a primary commodity (on average) and the top-three purchasing industries amount to $60 \%$ of total purchases by commodity (on average across commodities). In the Global Trade Analysis Project (GTAP) data, which are more aggregated (57 sectors), an average of 50\% of each commodity output is used by a single downstream sector. These high shares of top purchasers indicate fairly high specificity of each commodity. Furthermore, these input-output tables are much more aggregated than our commodity data, ${ }^{14}$ which conceals specialized uses across commodities. For instance, almost all iron ores are used in the production of steel, tungsten is used mainly in light bulbs and as tungsten carbide to strengthen cutting and drilling tools, nickel in stainless steel and magnets, phosphate in fertilizers, rare earth elements for electronics, crude petroleum in refineries, cocoa beans for chocolate, coffee beans for ground coffee, etc. Such specificity rarely appears in more aggregated industry-level input-output tables.

Commodity production also tends to be upstream relative to most other industries. This can be shown by examining the "upstreamness" index documented in Fally (2012), Antràs et al. (2012) and Fally and Hillberry (2018). In US input-output tables (Fally 2012), primary commodities other than fuels are associated with an upstreamness index of 3.01 (and 3.48 for fuels), while the same index is equal to 2.11 or less for manufacturing and services, indicating that commodities are separated on average by one more production stage from final demand.

Fact 6: Commodities are intensive in natural resources. Intuitively, sales of commodities are the main source of income associated with natural resources. Conversely, the production of primary commodities is intensive in natural resources. According to GTAP version 8 data, the returns to natural resources account for $31 \%$ of the costs of production across primary commodities. As depicted in Table 4, natural resource intensities vary largely across types of commodities and less

14. For instance, "Iron, gold, silver, and other metal ore mining" and "other minerals" (omn) constitute only one category in the US input-output tables and GTAP tables respectively. 
Table 4: Natural resource intensity in the GTAP 8 data

\begin{tabular}{llcc}
\hline \hline GTAP code & Commodity & Avg. resource intensity & Std. dev. \\
\hline coa & Mining and agglomeration of coal & 0.502 & $(0.160)$ \\
frs & Forestry & 0.153 & $(0.137)$ \\
fsh & Fishing & 0.448 & $(0.108)$ \\
gas & Extraction of natural gas & 0.205 & $(0.175)$ \\
oil & Oil extraction & 0.432 & $(0.133)$ \\
omn & Metal ores, mining n.e.c. & 0.179 & $(0.143)$ \\
(aggregate) & Agriculture & 0.242 & $(0.125)$ \\
\hline
\end{tabular}

Notes: share of land (agriculture) and natural resources (other than agriculture) in production costs by commodity on average; in parentheses: standard deviation across countries.

across countries - in a simple regression with country and industry fixed effects, industry variation accounts for half of the variance while country variation accounts for $11 \%$ of the variance.

Fact 7: For many countries, commodities and natural resources account for a large share of their income. Table 5 shows the countries in our sample ${ }^{15}$ for which natural resources constitute more than $25 \%$ of GDP, where natural resources are defined as rents from agriculture, forestry, minerals, and fuels. Most countries where natural resources compose a high share of GDP are developing countries, indicating that production and trade of products that use natural resources may be more important to developing countries than developed countries, which tend to have a comparative advantage in secondary and tertiary sectors.

\section{Fact 8: For many countries, a few commodities account for a large share of their total exports} and GDP. Defined at a similar level of aggregation as production data (a bit fewer than 170 primary commodities among thousands of traded products), one or only a handful of commodities account for majority of total exports for many countries. In Table 6 we list the countries in our sample for which one product constitutes more than $40 \%$ of that country's exports. Although it seems intuitive that this may be the case for smaller countries, this phenomenon is also the case in many large countries, especially low-income countries. Our sample encompasses only countries with a population of more than 1 million, but despite their size (e.g. Venezuela) exports in a single commodity make up more than $50 \%$ of exports for several of them. Several other countries have the majority of their exports consisting in only three primary commodities, such as Angola. Petroleum is a commodity in which many countries specialize, but other commodities may also account for very large export shares, such as cashew nuts for Guinea-Bissau and uranium for Eritrea.

This fact relates to Easterly and Reshef (2010) and Hanson et al. (2015) for overall exports. Such specialization leaves exporters especially vulnerable to price fluctuations in commodity prices,

15. We focus on countries with a population larger than 1 million. 
Table 5: Countries with the largest share of income from natural resources

\begin{tabular}{lr|lr|lr}
\hline \hline Country & $\begin{array}{r}\text { Income } \\
\text { Share }\end{array}$ & Country & $\begin{array}{r}\text { Income } \\
\text { Share }\end{array}$ & Country & $\begin{array}{r}\text { Income } \\
\text { Share }\end{array}$ \\
\hline Turkmenistan & 0.607 & Oman & 0.403 & Central African Rep. & 0.290 \\
Libya & 0.598 & Mongolia & 0.394 & Laos & 0.281 \\
Angola & 0.552 & Yemen & 0.351 & Brunei & 0.280 \\
Papua New Guinea & 0.526 & Congo & 0.349 & Ethiopia & 0.274 \\
Congo & 0.522 & Myanmar & 0.322 & Algeria & 0.269 \\
Iraq & 0.517 & Nigeria & 0.320 & Guinea-Bissau & 0.268 \\
Kuwait & 0.512 & Uzbekistan & 0.320 & Comoros & 0.267 \\
Equatorial Guinea & 0.502 & Liberia & 0.316 & Qatar & 0.255 \\
Saudi Arabia & 0.493 & Iran & 0.306 & Kazakhstan & 0.253 \\
Azerbaijan & 0.408 & Chad & 0.294 & Burundi & 0.252 \\
Gabon & 0.404 & Sierra Leone & 0.291 & Syria & 0.252 \\
\hline
\end{tabular}

Notes: Share of income from natural resources, countries for whom the share exceeds $25 \%$ of their total revenues in 2007. Source: World Bank, includes agriculture, forestry, minerals and fuel commodities.

which are common (see Table 2). For many developing countries, such price fluctuations in commodities can account for lower growth rates (Blattman et al. 2007, Drechsel and Tenreyro 2017). But these extreme specialization patterns also shed light on the large gains from trade that we find in our calibration. International trade creates a much larger relative demand in commodities than would be sustainable domestically in these highly-specialized countries.

Fact 9: For many commodities, a few countries account for most of the world's supply. The converse of Fact 8 is that there are numerous commodities for which a limited number of producers account for most of the world's supply. An example is copper, for which Chile accounts for $37 \%$ of world primary ore production, making it the world's largest producer. However, many commodities are even more geographically concentrated in terms of production than copper, including many agricultural products (canary seeds, almonds, garlic, etc.) and mineral products (rare earth metals, antimony, platinum, etc). As seen in Appendix Table 6, for many commodities, one producer accounts for more than $50 \%$ of production. Overall, in 2012, 39.5\% of the production of primary commodities in our sample came from countries responsible for the production of 50 percent or more of the world market. ${ }^{16}$

Notably, we also find a high degree of concentration in imports of many products, as shown in Table 11 in the Appendix. The results here are intuitive, as the main importers of some of these commodities tend to be the largest manufacturers (China, US, Japan). In addition, many of these commodities represent inputs into the production processes of downstream industries which may

16. Similarly, the same table documents the Herfindahl-Hirschman Index (HHI) on production of commodities across countries. We find that 81 commodities in our sample have HHI's above 0.25 in 2007 , indicating a high concentration of production in few countries. 
Table 6: Countries with the largest share of top commodity in total exports

\begin{tabular}{llc|llc}
\hline \hline Country & Top Commodity & Exports Share & Country & Top Commodity & Exports Share \\
\hline Iraq & Crude Oil & 0.990 & Burkina Faso & Cotton & 0.731 \\
Chad & Crude Oil & 0.945 & Tajikistan & Aluminium & 0.687 \\
Angola & Crude Oil & 0.930 & Gabon & Crude Oil & 0.663 \\
Guinea-Bissau & Cashews & 0.857 & Venezuela & Crude Oil & 0.658 \\
Nigeria & Crude Oil & 0.854 & Oman & Crude Oil & 0.631 \\
Iran & Crude Oil & 0.807 & Kuwait & Crude Oil & 0.614 \\
Azerbaijan & Crude Oil & 0.771 & Malawi & Tobacco & 0.558 \\
Saudi Arabia & Crude Oil & 0.770 & Mozambique & Aluminium & 0.555 \\
Congo & Crude Oil & 0.767 & Algeria & Crude Oil & 0.536 \\
Yemen & Crude Oil & 0.744 & Laos & Copper & 0.520 \\
Zambia & Copper & 0.738 & Jamaica & Alumina & 0.501 \\
Turkmenistan & Natural Gas & 0.737 & Kazakhstan & Crude Oil & 0.490
\end{tabular}

Notes: Share of top commodity in total exports by country in 2007, showing the countries with the highest concentration of exports that have a population larger than 1 million.

also be geographically concentrated in a few countries (e.g. cotton for Chinese textiles).

In some cases, these concentration patterns can be partially explained by the spatial allocation of natural resources necessary to produce these commodities. Although known deposits of minerals and fuels can expand with additional effort, exploration costs, and new technology, fundamentally, these resources are highly dispersed across countries. While this dispersion may seem limited to minerals and fuels, the land suitable for various agricultural commodities has a similar degree of dispersion across the world (see Appendix Figure 15 for plots of crop suitability for agricultural commodities with the highest worldwide total production value from 1970-2014). Even with high agricultural input levels, Global Agro-Ecological Zone (GAEZ) data from FAO/IIASA (2010) suggest that many countries are naturally unsuitable for staple agricultural commodities that represent a large share of agricultural production. Although use of technology and labor, such as irrigation, allows production to occur outside of areas highly suitable for agricultural production of a given product, it can only be done at a low productivity. Indeed, we find that production of agricultural commodities occurs largely within countries with land classified as suitable for agricultural production by the GAEZ data (see Appendix Figure 17 for plots of production of commodities by country for comparison). ${ }^{17}$

17. This relationship is not mechanical, as noted by Costinot and Donaldson (2012): the "parameters that enter the GAEZ model are estimated from countless field and lab experiments, not from statistical relationships between observed country-level output data and natural inputs". 
Table 7: Products with the highest concentration of exports from one country

\begin{tabular}{llll|llll}
\hline \hline Product & Largest & Export & Top 3 & Product & Largest & Export & Top 3 \\
& Exporter & Share & Share & & Exporter & Share & Share \\
\hline Canary seed & Canada & 0.837 & 0.909 & Bromine & Israel & 0.581 & 0.815 \\
Jute & Bangladesh & 0.776 & 0.876 & Rare Earths & China & 0.558 & 0.851 \\
Sorghum & USA & 0.731 & 0.869 & Figs & Turkey & 0.556 & 0.670 \\
Almonds & USA & 0.706 & 0.825 & Mandarins & Spain & 0.555 & 0.697 \\
Linseed & Canada & 0.671 & 0.794 & Buckwheat & China & 0.534 & 0.742 \\
Uranium & S. Africa & 0.667 & 0.994 & Germanium & Belgium & 0.530 & 0.936 \\
Oats & Canada & 0.631 & 0.774 & Barytes & China & 0.518 & 0.684 \\
Cassava & Thailand & 0.629 & 0.868 & Pineapples & Costa Rica & 0.514 & 0.669 \\
Garlic & China & 0.619 & 0.833 & Hops & Germany & 0.514 & 0.719 \\
Antimony & China & 0.611 & 0.773 & Sillimanite & S. Africa & 0.509 & 0.859 \\
Iodine & Chile & 0.607 & 0.858 & Lentils & Canada & 0.507 & 0.742 \\
Ginger & China & 0.591 & 0.734 & Mate & Brazil & 0.506 & 0.934 \\
Mustard seeds & Canada & 0.585 & 0.723 & Hazelnuts & USA & 0.503 & 0.797 \\
\hline
\end{tabular}

Notes: Share of exports from largest exporter and top-3 exporters for each HS6 product (or aggregated product).

\section{Theoretical framework}

The model closely follows standard multi-sector models of trade (Costinot and Rodríguez-Clare 2014, Caliendo and Parro 2015) featuring gravity-type equations for trade within each sector and inter-industry linkages. The main difference is that we emphasize the role of primary commodities and adapt the model to account for key features of primary commodity trade described in the previous section.

First, instead of assuming Cobb Douglas production functions, we allow for lower elasticities of substitution in production functions across different production stages in order to generate low demand and supply elasticities for commodities. Second, we introduce specific factors used to produce each commodity. This also contributes to lower supply elasticities and rationalizes the high concentration of commodity supply among a few exporters. ${ }^{18}$

We first present the general framework (Section 2.1). Then we introduce the "exact hat algebra" used to describe counterfactual equilibria and simulate the effect of a change in trade costs (Section 3.2). Next, we move on to describe the gains from trade relative to autarky and examine special cases where we can provide closed-form solutions for the gains from trade (Section 2.3).

18. We obtain Figure 1 in the introduction if we reduce the model to two commodities and one final good. 


\subsection{Setting and equilibrium conditions}

There are potentially many countries, indexed by $n$ or $i$. There are two types of goods: final goods $k$ (downstream industries) and commodities $g$ (upstream). Production of final goods $k$ relies on labor and primary commodities $g$. In turn, the production function of commodities is a constant elasticity of substitution (CES) combination between natural resources and labor. Production features constant returns to scale under perfect competition in all sectors of the economy. Both commodities $g$ and final goods $k$ can be traded.

Demand for final goods We assume that utility has constant elasticity of substitution across final goods $k$, with elasticity $\sigma$. Expenditure in final good $k$ in destination $n$, denoted by $D_{n k}^{F}$, is:

$$
D_{n k}^{F}=\left(P_{n k}^{F} / P_{n}^{F}\right)^{1-\sigma} a_{n k} E_{n}
$$

where $E_{n}$ refers to total expenditures in country $n, a_{n k}$ is a good-by-country-specific utility shifter, and where the overall consumer price index $P_{n}^{F}$ is defined as:

$$
P_{n}^{F}=\left[\sum_{k} a_{n k}\left(P_{n k}^{F}\right)^{1-\sigma}\right]^{\frac{1}{1-\sigma}}
$$

Note that, in turn, we could model each final good sector $k$ as the aggregation of a continuum of product varieties with a CES sub-utility function involving an elasticity of substitution that may differ from $\sigma$. Following Eaton and Kortum (2002), Costinot et al. (2011), Caliendo and Parro (2015) among others, one could assume that the consumption bundle in industry $k$ is a CES aggregate of a continuum of varieties $\omega_{k} \in(0,1)$ such that: $Q_{n k}=\left(\int_{\omega_{k}=0}^{1} q_{n k}\left(\omega_{k}\right)^{\frac{\xi_{k}-1}{\xi_{k}}} d \omega_{k}\right)^{\frac{\xi_{k}}{\xi_{k}-1}}$ with elasticities $\xi_{k}$. Such elasticities $\xi_{k}$ may be allowed to differ across sectors $k$ (and even across countries) but they would play no role here and would not alter the counterfactuals equilibrium conditions described in the next sections. On the contrary, the elasticity of substitution $\sigma$ across broad types of goods can potentially play an important role.

Trade in final goods $k$ As common in the trade literature, we assume iceberg transport costs $\tau_{n i k} \geq 1$ from country $i$ to country $n$ in sector $k$. We denote by $C_{i k}^{F}$ the cost of producing goods $k$ in country $i$, such that the cost of supplying these goods in destination $n$ is given by $\tau_{n i k} C_{i k}^{F}$ once we adjust for trade costs.

We then assume that trade follows the typical "gravity" equation within each sector. In brief, 
we assume that trade in final goods $k$, from $i$ to $n$ is given by:

$$
X_{n i k}^{F}=\frac{\left(C_{i k}^{F} \tau_{n i k}\right)^{-\theta_{k}}}{\sum_{j}\left(C_{j k}^{F} \tau_{n j k}\right)^{-\theta_{k}}} D_{n k}^{F} \equiv \lambda_{n i k} D_{n k}^{F}
$$

where $\theta_{k}$ denotes the elasticity of trade to trade costs. In this framework, the price index of goods $k$ in destination country $n$ is then a CES function of the cost of producing these goods across source countries $i$ :

$$
P_{n k}^{F}=\left[\sum_{i}\left(C_{i k}^{F} \tau_{n i k}\right)^{-\theta_{k}}\right]^{-\frac{1}{\theta_{k}}}
$$

Such outcomes for trade flows and price indexes ("gravity equations") can be micro-founded and obtained under various alternative sets of assumptions: i) under perfect competition and perfect substitution with a continuum of varieties (Eaton and Kortum 2002 and related literature), ii) under perfect competition and imperfect substitution across source countries (Anderson 1979) as in the CGE literature; iii) under imperfect competition with homogeneous productivity (Krugman 1980) or heterogeneous productivity (Chaney 2008).

For instance, following Eaton and Kortum (2002), Costinot et al. (2011), Caliendo and Parro (2015), one could assume that there is a continuum of varieties $\omega_{k}$ with random productivity draw $Z_{i k}\left(\omega_{k}\right)$ and perfect competition such that the price would equal:

$$
p_{n k}\left(\omega_{k}\right)=\min _{i}\left\{\frac{\tau_{n i k} C_{i k}^{F}}{Z_{i k}\left(\omega_{k}\right)}\right\}
$$

in each destination country $n$, after taking the minimum across the costs of production and shipment across source countries $i$. If we further assume that productivity $Z_{i k}\left(\omega_{k}\right)$ is drawn independently across countries $i$ and sectors $k$ from a Frechet distribution: $F_{i k}(z)=\exp \left[-\left(z / z_{i k}\right)^{-\theta_{k}}\right]$, we obtain exactly the same equilibrium conditions as those described above and the same counterfactual conditions as in the following sections.

Multi-sector extensions of Anderson (1979), Krugman (1980) and Chaney (2008) would also provide frameworks that would yield the same equilibrium conditions as those described above, i.e. lead to gravity equations within sectors, with price indexes satisfying (4). See Arkolakis et al. (2012), Costinot and Rodríguez-Clare (2014) and Anderson (2011) for discussion of the equivalence between these models.

Production of final goods $k$ For each good $k$, we assume constant elasticity production functions with constant returns to scale and elasticity of substitution $\eta_{k}$ between inputs. As discussed previously, we assume that sector $k$ relies on labor and a set of commodities $g \in G(k)$. Thus, de- 
noting labor wages by $w_{i}$ and the price of commodity $g$ by $P_{i g}^{C}$, the cost of producing final good $k$ in producing country $i$ can be written as:

$$
C_{i k}^{F}=A_{i k}^{F}\left[\beta_{i k, L}^{F} w_{i}^{1-\eta_{k}}+\sum_{g} \beta_{i k, g}^{F}\left(P_{i g}^{C}\right)^{1-\eta_{k}}\right]^{\frac{1}{1-\eta_{k}}}
$$

This cost function allows for productivity terms $A_{i k}^{F}$ as well as factor requirements $\beta_{i k, L}^{F}$ (for labor) and $\beta_{i k, g}^{F}$ (for commodity $g$ ) that may vary across sectors $k$ and countries $i$ to reflect differences in technology. We will denote by $\varphi_{i k, L}$ and $\varphi_{i k, g}$ the share of labor and commodity $g$ in total costs.

Under these assumptions, Shephard's Lemma yields the following expenditures (demand) in commodity $g$ in destination $i$ by industry $k$ :

$$
D_{i g k}^{C}=\beta_{i k, g}^{F}\left(P_{i g}^{C} / C_{i k}^{F}\right)^{1-\eta_{k}} Y_{i k}^{F}
$$

where $Y_{i k}^{F}=\sum_{n} X_{n i k}^{F}$ denotes production value of good $k$ in $i$. We obtain total demand $D_{i g}^{C}$ for commodity $g$ by summing across downstream industries: $D_{i g}^{C}=\sum_{k} D_{i g k}^{C}$.

Assuming that a given commodity $g$ corresponds to a small share of total costs of downstream industries $k$, and holding $Y_{i k}$ and wages $w_{i}$ constant, the price elasticity of demand in commodity $g$ is approximately given by $\eta_{k}$ :

$$
\frac{\partial \log \left(D_{i g k}^{C} / P_{i g}^{C}\right)}{\partial \log P_{i g}^{C}} \approx-\eta_{k}
$$

We will subsequently use this property to calibrate $\eta_{k}$ and account for the low demand elasticities facing most primary commodities (see Section 3).

Trade in commodities $g$ For primary commodities, we adopt the same assumptions for trade as for final goods $k$, although we allow trade costs $\tau_{\text {nig }}$ and trade elasticities $\theta_{g}$ to differ from those associated with final goods $k$. We assume that trade for commodity $g$ from $i$ to $n$ is given by:

$$
X_{n i g}^{C}=\frac{\left(C_{i g}^{C} \tau_{n i g}\right)^{-\theta_{g}}}{\sum_{j}\left(C_{j g}^{C} \tau_{n j g}\right)^{-\theta_{g}}} D_{n g}^{C} \equiv \lambda_{n i g}^{C} D_{n g}^{C}
$$

while the price index of commodity $g$ in destination $n$ :

$$
P_{n g}^{C}=\left[\sum_{i}\left(C_{i g}^{C} \tau_{n i g}\right)^{-\theta_{g}}\right]^{-\frac{1}{\theta_{g}}}
$$

where $C_{i g}^{C}$ denotes the cost of producing commodity $g$ in source country $i$. 
Production of commodities $g$ In turn, the cost of producing commodities is again a CES function of factor prices. We assume that the production of a commodity $g$ in country $i$ uses two inputs: labor and natural resources that are specific to commodity $g$, such as minerals or oil reserves, with an elasticity of substitution $\rho_{g}$ between them. ${ }^{19}$ If we denote by $r_{i g}$ the price of natural resources for commodity $g$, the cost of producing commodity $g$ is:

$$
C_{i g}^{C}=A_{i g}^{C}\left[\beta_{i g}^{C} r_{i g}^{1-\rho_{g}}+\left(1-\beta_{i g}^{C}\right) w_{i}^{1-\rho_{g}}\right]^{\frac{1}{1-\rho_{g}}}
$$

Two features of this cost equation can influence the supply elasticity of commodity $g$ : i) assuming that the supply of natural resources is fixed, a higher share of natural resources in total costs leads to a lower elasticity of supply; ii) a lower elasticity of substitution $\rho_{g}$ between labor and natural resources also lead to a lower elasticity of supply. Holding wages and natural resources fixed, the price elasticity of supply is:

$$
\frac{\partial \log \left(Y_{i g}^{C} / C_{i g}^{C}\right)}{\partial \log C_{i g}^{C}}=\frac{\rho_{g} \varphi_{i g, L}}{\varphi_{i g, R}}
$$

where $\varphi_{i g, R}$ and $\varphi_{i g, L}=1-\varphi_{i g, R}$ denote the share of natural resources and labor in the total production cost of commodity $g$.

Sources of income Since there are two types of factors of production, labor (mobile across industries) and natural resources (specific to each commodity), there are also two types of income sources.

Income from natural resources associated with commodity $g$ is $R_{i g} r_{i g}$, where $R_{i g}$ is the (fixed) endowment in natural resources. In equilibrium, it equals the value of production of commodity $g$ in country $i$ multiplied by the share of natural resources in the production costs of this commodity:

$$
R_{i g} r_{i g}=\beta_{i g}^{C}\left(r_{i g} / C_{i g}^{C}\right)^{1-\rho_{g}} Y_{i g}^{C}
$$

where $Y_{i g}^{C}=\sum_{n} X_{\text {nig }}^{C}$ denotes the production of commodity $g$ in country $i$.

In turn, income from labor in country $i$ stems from all sectors of the economy: final goods sectors $k$ and commodity sectors $g$. We denote by $L_{i}$ the mass of workers in country $i$, assumed to be fixed. In equilibrium, income from labor is determined by:

$$
L_{i} w_{i}=\sum_{g}\left(1-\beta_{i g}^{C}\right)\left(w_{i} / C_{i g}^{C}\right)^{1-\rho_{g}} Y_{i g}^{C}+\sum_{k} \beta_{i k, L}^{F}\left(w_{i} / C_{i k}^{F}\right)^{1-\eta_{k}} Y_{i k}^{F}
$$

19. Although mineral resources are certainly in finite supply, extracting costs increase with the required supply of the commodity. Here the convexity in costs is generated by the use of another input that is mobile (labor), which has to increase in order to produce larger amounts of that commodity. We refer to that common input as labor, but one could think of it as additional machines and technologies required to extract larger amounts from natural resources. 
where $Y_{i k}^{F} \equiv \sum_{n} X_{n i k}^{F}$ and $Y_{i g}^{C} \equiv \sum_{n} X_{n i g}^{C}$ denote the production of final good $k$ and commodity $g$ respectively.

Finally, we obtain total income (also total GDP) by summing income across all sources:

$$
E_{n}=w_{n} L_{n}+\sum_{g} r_{n g} V_{n g}
$$

For now, we assume away any trade deficit on aggregate, hence income equals total expenditures.

Equilibrium An equilibrium is defined as the solution in $\left(D_{n k}^{F}, P_{n}^{F}, X_{n i k}^{F}, P_{n k}^{F}, C_{n k}^{F}, D_{n g}^{C}, X_{n i g}^{C}, P_{n g}^{C}\right.$, $\left.C_{n g}^{C}, r_{n g}, w_{n}, E_{n}\right)$ satisfying equations (1) to (13).

\subsection{Counterfactual equilibria}

\subsubsection{Exact hat algebra}

Assuming that the world economy is in equilibrium, we are primarily interested in how a change in trade costs and other key parameters will affect the equilibrium and how it will affect welfare across countries, i.e. the ratio of income to final goods prices $E_{n} / P_{n}^{F}$.

As in Dekle et al. (2008) and Caliendo and Parro (2015) among many others, the model lends itself naturally to counterfactual simulations in general equilibrium. By rewriting the above equilibrium conditions in terms of changes relative to the baseline observed equilibrium, the problem can be formulated as a function of a set of observed variables and only a few parameters to estimate. We do so with the help of the "exact hat" notation, without involving approximations, where $\widehat{Z}=Z^{\prime} / Z$ denotes the relative change, and $Z^{\prime}$ refers to the value in the new equilibrium.

Counterfactual equilibrium The change in equilibrium outcomes $\left(\widehat{D}_{n k}^{F}, \widehat{P}_{n}, \widehat{X}^{F}{ }_{n i k}, \widehat{P}^{F}{ }_{n k}, \widehat{C}^{F}{ }_{n k}\right.$, $\left.\widehat{D}_{n g}^{C}, \widehat{X}_{n i g}, \widehat{P}_{n g}, \widehat{C}_{n g}, \widehat{r}_{n g}, \widehat{w}_{n}, \widehat{E}_{n}\right)$ is the solution to the following set of equations:

$$
\begin{aligned}
\widehat{E}_{i} & =e_{i L} \hat{w}_{i}+\sum_{g} e_{i g, R} \hat{r}_{i g} \\
\widehat{P_{n}^{F}} & =\left[\sum_{k} \alpha_{n k} \widehat{P}_{n k}^{1-\sigma}\right]^{\frac{1}{1-\sigma}} \\
\widehat{P_{n k}^{F}} & =\left[\sum_{i} \lambda_{n i k}^{F}\left(\widehat{C}_{i k} \widehat{\tau_{n i k}}\right)^{-\theta_{k}}\right]^{-\frac{1}{\theta_{k}}} \\
\widehat{P_{n g}^{C}} & =\left[\sum_{i} \lambda_{n i g}^{C}\left(\widehat{C}^{C} \widehat{\tau}_{\text {侻 }}\right)^{-\theta_{g}}\right]^{-\frac{1}{\theta_{g}}}
\end{aligned}
$$




$$
\begin{aligned}
& \widehat{D_{n k}^{F}}=\left(\frac{\widehat{P_{n k}^{F}}}{\widehat{P_{k}^{F}}}\right)^{1-\sigma} \widehat{E_{n}} \\
& \widehat{D_{n g}^{C}}=\sum_{k} d_{n k g}\left(\frac{\widehat{P_{n g}^{C}}}{\widehat{C_{n k}^{F}}}\right)^{1-\eta_{k}} \widehat{Y_{n k}^{F}} \\
& \widehat{Y_{i k}^{F}}=\sum_{n}\left(X_{n i k}^{F} / Y_{i k}^{F}\right)\left(\widehat{C}^{F} \widehat{\tau}_{n i k}\right)^{-\theta_{k}}\left(\widehat{P}_{n k}\right)^{\theta_{k}} \widehat{D_{n k}^{F}} \\
& \widehat{Y_{i g}^{C}}=\sum_{n}\left(X_{n i g}^{c} / Y_{i g}^{C}\right)\left(\widehat{C}_{i g} \widehat{\tau_{n i g}}\right)^{-\theta_{g}}\left({\widehat{P^{C}}}_{n g}\right)^{\theta_{g}} \widehat{D_{n g}^{C}} \\
& \widehat{C_{i k}^{F}}=\left[\varphi_{i k, L} \hat{w}_{i}^{1-\eta_{k}}+\sum_{g} \varphi_{i k, g}\left(\widehat{P_{i g}^{C}}\right)^{1-\eta_{k}}\right]^{\frac{1}{1-\eta_{k}}} \\
& \widehat{C_{i g}^{C}}=\left[\varphi_{i g, R} \hat{r}_{i g}^{1-\rho_{g}}+\varphi_{i g, L} \hat{w}_{i}^{1-\rho_{g}}\right]^{\frac{1}{1-\rho_{g}}} \\
& \hat{r}_{i g}=\left(\hat{r}_{i g} / \widehat{C_{i g}^{C}}\right)^{1-\rho_{g}} \widehat{Y_{i g}^{C}} \\
& \hat{w}_{i}=\sum_{g}\left(\varphi_{i g, L} Y_{i g}^{C} / w_{i} L_{i}\right)\left(\hat{w}_{i} / \widehat{C_{i g}^{C}}\right)^{1-\rho_{g}} \widehat{Y_{i g}^{C}}+\sum_{k}\left(\varphi_{i k, L} Y_{i k}^{F} / w_{i} L_{i}\right)\left(\hat{w}_{i} / \widehat{C_{i k}^{F}}\right)^{1-\eta_{g}} \widehat{Y_{i k}^{F}}
\end{aligned}
$$

These equations are formulated in terms of the key elasticities of the model: $\sigma, \eta_{k}, \rho_{g}, \theta_{k}$ and $\theta_{g}$, as well as observable outcomes that describe the initial equilibrium: the share of labor and resources in $g$ in total income in the baseline equilibrium, $e_{n L}=\frac{w_{n} L_{n}}{E_{n}}$ and $e_{n g}=\frac{r_{n g} V_{n g}}{E_{n}}$ respectively; the expenditure share of good $k$ in the baseline equilibrium, $\alpha_{n k}$; the share of industry $k$ in total demand for commodity $g$ in each country $i, d_{i k g}$; import shares, $\lambda_{\text {nik }}^{F}$ and $\lambda_{\text {nig }}^{C}$ (equations 3 and 7); the share of labor in manufacturing costs $\varphi_{i k, L}$ and the share of commodity $g$ in manufacturing costs, $\varphi_{i k, g}$; the share of labor and resources in the production costs of commodity $g: \varphi_{i g, R}$ and $\varphi_{i g, L}$. These shares can be directly observed in the data and they are easier to calibrate than the model primitives that enter equilibrium equations (1) to (13). Note that we can ignore one of the equilibrium conditions above for a reference country (Walras Law) and make one normalization if the above shares are consistent with equilibrium (see Appendix).

\subsubsection{Gains from trade}

One can further link the gains from trade to changes in key equilibrium outcomes. With constant elasticities of substitution, one can relate the change in prices to the cost of a specific input or good, adjusting for the change in the share of that input or good. This can be applied to price indexes (Feenstra 1994), gains from trade (Arkolakis et al. 2012), production costs (Blaum et al. 2015), or other features. In our framework, this insight can be applied to several equilibrium outcomes. For the gains from trade in a particular industry $k$ or commodity $g$ (as in Arkolakis et al. (2012)), we 
have:

$$
\widehat{P_{i k}^{F}}=\widehat{\lambda}_{i i k}^{-\frac{1}{\theta_{k}}} \widehat{C}_{i k}^{F} \quad ; \quad \widehat{P_{i g}^{C}}=\widehat{\lambda}_{i i g}^{-\frac{1}{\theta_{g}}} \widehat{C_{i g}^{C}}
$$

where $\lambda_{i i k}^{F}$ and $\lambda_{i i k}^{C}$ denotes the share of domestic production in demand in country $i$ for good $k$ and commodity $g$ respectively. Applying the same tools to the share of inputs in production functions, we link the change in total costs to the share of labor, commodities or natural resources and their unit costs:

$$
\widehat{C_{i k}^{F}}=\widehat{\varphi_{i k, L}}-\frac{1}{1-\eta_{k}} \hat{w}_{i} \quad \widehat{C_{i k}^{F}}=\widehat{\varphi_{i k, g}}-\frac{1}{1-\eta_{k}} \widehat{P_{i g}^{C}} \quad ; \quad \widehat{C_{i g}^{C}}=\widehat{\varphi_{i g, R}}-\frac{1}{1-\eta_{k}} \widehat{r_{i g}}
$$

Applying the same trick to final goods shares, we also have: $\widehat{P_{i}^{F}}=\widehat{\alpha_{i k}}-\frac{1}{1-\sigma} \widehat{P_{i k}^{F}}$.

Combining the first two equations, the gains from trade for workers are given by:

$$
G T_{i}^{L}=\widehat{P_{i}^{F}}=\left[\sum_{k} \alpha_{i k}{\widehat{P_{i k}^{F}}}^{1-\sigma}\right]^{\frac{1}{1-\sigma}}=\left[\sum_{k} \alpha_{i k} \widehat{\lambda}_{i i k}^{-\frac{1-\sigma}{\theta_{k}}} \widehat{\varphi}_{i k, L}^{-\frac{1-\sigma}{1-\eta_{k}}}\right]^{\frac{1}{1-\sigma}}
$$

where $\hat{w}_{i}$ is normalized to unity. As a first-order approximation, the upper-level elasticity $\sigma$ does not play an important role. However, this expression suggests that elasticities of substitution $\eta_{k}$ can greatly influence the gains from trade in commodities, with larger gains from trade when $\eta_{k}$ is smaller, conditional on the change in a commodity cost share.

For factors $g$, we can link welfare gains from trade to the change in input shares of commodity $g$ and resources $g$. Using the tools described above, we obtain the following change in revenues for natural resources $g$ (relative to labor), which holds for any industry $k$ with a positive demand for that commodity:

$$
\widehat{r_{i g}}=\widehat{\lambda_{i i g}^{C}} \frac{1}{\theta_{g}} \widehat{\varphi_{i g, R}} \frac{1}{1-\rho g}\left(\widehat{\varphi_{i k, g}} / \widehat{\varphi_{i k, L}}\right)^{\frac{1}{1-\eta_{k}}}
$$

and the change in real income for resource owners $G T_{i g}^{R}=\widehat{P_{i}^{F}} / \widehat{r_{i g}}$. Both these expressions highlight the role of $\eta_{k}$ and $\rho_{g}$, which can both magnify the gains from trade. In addition, as we will describe in our calibration, lower $\eta_{k}$ and $\rho_{g}$ also lead to larger changes in input shares $\widehat{\varphi_{i k, L}}, \widehat{\varphi_{i k, g}}$ and $\widehat{\varphi_{i g, R}}$.

Finally, since $\widehat{E}_{i}=e_{i L}+\sum_{g} e_{i g} \widehat{r_{i g}}$, aggregate gains can be computed by taking the harmonic average of the previous two expressions: $1 / G T_{i}=e_{i L} / G T_{i}^{L}+\sum_{g} e_{i g} / G T_{i g}^{R}$.

\subsection{Comparison to autarky}

Of particular interest are the gains from trade relative to complete autarky. In some special cases, we can obtain analytical expressions for the gains from trade, which we discuss below.

Some of the above equations describing the changes from baseline equilibrium to autarky can be simplified in this case. Trade costs are now such that $\widehat{\tau_{\text {nik }}}=+\infty$ and $\widehat{\tau_{\text {nig }}}=+\infty$ whenever $n \neq i$. 
Furthermore, production has to equal demand in autarky for each good $k$ and commodity $g$. Hence, we have equalities $D_{n k}^{F} \widehat{D_{n k}^{F}}=Y_{n k} \widehat{Y_{n k}}$ and $D_{n g}^{C} \widehat{D_{n g}^{C}}=Y_{n g} \widehat{Y_{n g}}$ which we can use to combine equations in demand and production. Equations (16) to (21) can then be replaced by the following set of equations:

$$
\begin{array}{lll}
\widehat{P_{n k}^{F}}=\left(\lambda_{n n k}^{F}\right)^{-\frac{1}{\theta_{k}}} \widehat{C_{n k}^{F}} \quad & ; & \widehat{Y_{n k}}=\left(\frac{\widehat{P_{n k}^{F}}}{\widehat{P_{k}^{F}}}\right)^{1-\sigma} \widehat{E_{n}} \frac{D_{n k}^{F}}{Y_{n k}} \\
\widehat{P_{n g}^{C}}=\left(\lambda_{n n g}^{C}\right)^{-\frac{1}{\theta_{g}}} \widehat{C_{n g}^{C}} \quad ; & \widehat{Y_{n g}}=\frac{D_{n g}^{C}}{Y_{n g}} \sum_{k} \tau_{n k g} \widehat{Y_{n k}^{F}}\left(\frac{\widehat{P_{n g}^{C}}}{\widehat{C_{n k}^{F}}}\right)^{1-\eta_{k}}
\end{array}
$$

while other equations (14), (15) and (22) to (25) remain the same.

\section{Closed-form solutions when demand and supply elasticities are equal}

Resource income First, when supply and demand elasticities are equal, $\rho_{g}=\eta_{k} \equiv \eta$, one can express the change in revenues from natural resources as a function of the change in production and costs in downstream industries:

$$
\hat{r}_{i g}=\left(\lambda_{i i g}^{C}-\frac{1-\eta}{\theta g} \frac{D_{i g}^{C}}{Y_{i g}^{C}} \sum_{k} d_{i k g} \frac{\widehat{Y_{i k}^{F}}}{{\widehat{C_{i k}^{F}}}^{1-\eta}}\right)^{\frac{1}{\eta}}
$$

and thus the change in income, using equation (14). In this expression, one can see that autarky leads to larger income $r_{i g}$ if initial demand exceeds production and if the product is purchased by downstream industries with the highest cost increases $C_{i k}^{F}$ by switching to autarky. The change in revenues is also magnified when the elasticity $\eta$ is smaller (as it is the case with most commodities, see Fact 2).

Using equation (23), $\widehat{C}_{i g}^{1-\eta}=\varphi_{i g, L}+\varphi_{i g, R} \hat{r}_{i g}^{1-\eta}$, we can also obtain production costs for commodity $g$ and downstream industry $k$, which greatly reduces the dimensionality of the problem.

Gains from trade We obtain a model with analytical solutions for the gains from trade if, in addition to the equality between supply and demand elasticities in commodity markets, we also assume that these elasticities are equal to the consumption elasticity of substitution between broad groups of final goods $k$, i.e. assuming $\rho_{g}=\eta_{k}=\sigma$ across all industries $k$ and commodities $g$. The main source of tractability in this special case is that the changes in price indexes due to the changes in natural resources revenues $\hat{r}_{i g}$ are proportional to $e_{i L}$, the share of revenues in total income. ${ }^{20}$

20. Thanks to this property, we also obtain: $\widehat{E}_{i} / \widehat{P}_{i}^{1-\sigma}=1 / \Lambda_{i}^{1-\sigma}$. See Appendix for details. 
Using this property, we obtain that the change in income for resources $g$ is given by:

$$
\hat{r}_{i g}=\left(\lambda_{i g}^{C-\frac{1-\sigma}{\theta g}} \Lambda_{i}^{\sigma-1} \frac{D_{i g}^{C}}{Y_{i g}^{C}} \sum_{k} \frac{d_{i k g} D_{i k}^{F}}{Y_{i k}^{F}} \lambda_{i k}^{F^{-\frac{1-\sigma}{\theta_{k}}}}\right)^{\frac{1}{\sigma}}
$$

where $\Lambda_{i}$ is defined as:

$$
\Lambda_{i}^{1-\sigma} \equiv \frac{1}{e_{i L}} \sum_{k} \alpha_{k} \lambda_{i k}^{F^{-\frac{1-\sigma}{\theta_{k}}}}\left[\varphi_{i k, L}+\sum_{g} \varphi_{i k, g} \varphi_{i g, L} \lambda_{i g}^{C^{-\frac{1-\sigma}{\theta_{g}}}}\right]
$$

This expression highlights the role of relative supply and demand for commodity $g$ in the initial equilibrium, as well as commodity-industry linkages and the relative supply and demand in downstream industries $k$. Again, these changes are magnified when elasticity $\sigma$ is small.

We can also obtain analytical expressions for the changes in price indexes and overall GDP, as well as the aggregate gains from trade.

Proposition 1 Relative to autarky, the aggregate gains from trade are:

$$
G T_{i}=\left[e_{i L} \Lambda_{i}^{\frac{1-\sigma}{\sigma}}+\sum_{g} e_{i g, R}\left(\lambda_{i g}^{C}-\frac{1-\sigma}{\theta g} \frac{D_{i g}^{C}}{Y_{i g}^{C}} \sum_{k} \frac{d_{i k g} D_{i k}^{F}}{Y_{i k}^{F}} \lambda_{i k}^{F^{-\frac{1-\sigma}{\theta_{k}}}}\right)^{\frac{1}{\sigma}}\right]^{\frac{\sigma}{1-\sigma}}
$$

if we assume that $\rho_{g}=\eta_{k}=\sigma$, where $\Lambda_{i}$ is defined as above (equation 34).

In this expression, $\Lambda_{i}$ corresponds to the gains from trade if labor is the only input in the production of primary commodities (no natural resources). The absence of a role for natural resources greatly reduces the gains from trade since the production of a required commodity is no longer tied to a country's endowment in natural resources. In general, we obtain that the gains from trade are larger than without natural resources, as we will illustrate quantitatively in our counterfactual simulations.

We can further compute the gains from trade for workers and for natural resource owners separately. For workers, whose wages are normalized $\left(\widehat{w}_{i}=1\right)$, the gains from trade are given by how much the price index would increase in autarky relative to the baseline equilibrium:

$$
\widehat{P F}_{i}=\Lambda_{i}\left[e_{i L}+\sum_{g} e_{i g, R} \hat{r}_{i g}\right]^{\frac{1}{1-\sigma}}
$$

while the gains from trade for natural resource owners in commodity $g$ are given by $\widehat{P_{i}^{F}} / \hat{r}_{i g}$, using the solutions above for $\widehat{P F}_{i}$ and $\hat{r}_{i g}$ (equation 33). 
In the Appendix, we describe two special cases where the formula is more simple: with a single downstream industry (to be used when input-output linkage data are not available) and with homogeneous commodities (limit case with infinite trade elasticities $\theta_{g}=+\infty$ ).

\subsection{Two alternative model specifications}

\subsubsection{Choke prices}

A critical aspect of production functions with a constant elasticity of substitution that remains below unity is that the cost goes to infinity as the price of a single commodity goes to infinity. Hence, the losses of going to autarky are infinite for any country that cannot produce a specific commodity but has a positive demand for it, since it leads to infinite prices.

One may argue, however, that technology or sufficient effort might provide a substitute for a commodity at a finite cost. To allow for such a possibility, and to allow for a higher elasticity of substitution when a specific commodity becomes too expensive, we consider an alternative production function for downstream industries that leads to a choke price in each commodity, i.e. a finite price level above which demand for that commodity is null. Specifically, we consider the following production function:

$$
C_{i k}^{F}=\left[\beta_{i k, L}^{F} w_{i}^{1-\eta_{k}}+\sum_{g} \beta_{i k, g}^{F}\left(\left(P_{i g}^{C}\right)^{1-\eta_{k}}-\left(1-\eta_{k}\right) P_{i g}^{C}\left(a_{i g} w_{i}\right)^{-\eta_{k}}\right)\right]^{\frac{1}{1-\eta_{k}}}
$$

for as long as $\frac{\partial C_{i k}^{F}}{\partial P_{i g}^{C}} \geq 0$, i.e. as long as $P_{i g}^{C} \leq a_{i g} w_{i}$, where $a_{i g}$ is a constant term. This leads to a demand curve for each commodity that is a leftward translation of the standard CES demand curve

$$
\frac{D_{i g k}^{C}}{P_{i g}^{C}}=\max \left\{0, \beta_{i k, g}^{F}\left(\left(P_{i g}^{C}\right)^{-\eta_{k}}-\left(a_{i g} w_{i}\right)^{-\eta_{k}}\right) \cdot \frac{Y_{i k}^{F}}{\left(C_{i k}^{F}\right)^{1-\eta_{k}}}\right\}
$$

with a choke price $P_{i g}^{*}=a_{i g} w_{i}$. The elasticity of the share of commodity $g$ in manufacturing costs with respect to the price of commodity $g$ here is given by:

$$
\frac{\partial \log \varphi_{i k, g}}{\partial \log P_{i g}^{C}}-1=-\frac{\eta_{k}}{1-\Delta_{i g}}
$$

where we define $\Delta_{i g}$ as the relative gap to the choke price: $\Delta_{i g}=\left(a_{i g} w_{i} / P_{i g}^{C}\right)^{-\eta_{k}} \leq 1$.

We then express the counterfactual changes in costs and demand for commodities as a function 
the relative gap $\Delta_{i g}$ :

$$
\begin{aligned}
\widehat{D_{n g k}^{C}} & =\left(\frac{1-\Delta_{i g}\left(\widehat{P}_{n g}^{C} / \widehat{w}_{i}\right)^{\eta_{k}}}{1-\Delta_{i g}}\right) \frac{\widehat{P}_{n g}^{1-\eta_{k}} \widehat{Y}_{n k}^{F}}{\widehat{C}_{n k}^{1-\eta_{k}}} \\
{\widehat{C_{i k}^{F}}}^{1-\eta_{k}} & =\varphi_{i k, L} \hat{w}_{i}^{1-\eta_{k}}+\sum_{g} \varphi_{i k, g} \widehat{P}_{i g}^{1-\eta_{k}}+\sum_{g} \frac{\varphi_{i k, g} \Delta_{i g}}{1-\Delta_{i g}}\left[\widehat{P}_{i g}^{1-\eta_{k}}-\eta_{k} \hat{w}_{i}^{1-\eta_{k}}-\left(1-\eta_{k}\right) \widehat{P}_{i g}^{C} \hat{w}_{i}^{-\eta_{k}}\right]
\end{aligned}
$$

where the CES case can be seen as the limit case where $\Delta_{i g}=0$. The higher is $\Delta_{i g}$, the lower the potential loss from trade as prices are close to their upper limit.

\subsubsection{Land allocation}

In our baseline model, each commodity relies on a specific natural resource. Instead, one could argue that natural resources, such as land, can be used to produce any commodity, with varying productivities. To do so, we assume a production function in one input (land) with a constant elasticity of transformation between outputs. This generates a productivity possibility frontier (PPF) that is sufficiently concave, which reflects the low elasticity of supply for commodities. This specification is equivalent to other studies in the trade literature modeling land allocation (Costinot et al. 2016) and labor allocation (Galle et al. 2017) across crops, tasks, or industries. A constant elasticity of transformation PPF as here is isomorphic to production with heterogeneous inputs (heterogeneous land parcels or heterogeneous workers) whose productivity for each type of output (crop or industry) is drawn independently from a Frechet distribution for which the distribution parameter is identical across crops or industries.

Specifically, we assume that land can be used to produce any commodity $g$ with productivity $A_{i g}$ such that the following constraint holds:

$$
\sum_{g}\left(Q_{i g} / A_{i g}\right)^{\frac{1+\rho}{\rho}}=T_{i}^{\frac{1+\rho}{\rho}}
$$

For a given set of prices, maximizing the overall value of production leads to the following production value for commodity $g$ :

$$
Y_{i g}=A_{i g}^{1+\rho} C_{i g}^{1+\rho} T_{i} \Phi_{i}^{-\rho}=\pi_{i g}^{T} T_{i} \Phi_{i}
$$

where $\Phi_{i}=\left(\sum_{g} A_{i g}^{1+\rho} C_{i g}^{1+\rho}\right)^{\frac{1}{1+\rho}}$ corresponds to the value of a parcel of land (i.e. corresponds to a 
commodity producer price index) and where

$$
\pi_{i g}^{T}=\frac{A_{i g}^{1+\rho} C_{i g}^{1+\rho}}{\sum_{g^{\prime}} A_{i g^{\prime}}^{1+\rho} C_{i g^{\prime}}^{1+\rho}}
$$

is both the share of land $T_{i}$ devoted to the production of commodity $g$ and the share of land income associated with commodity $g$. Total income from land is then given by $\sum_{g} Y_{i g}=T_{i} \Phi_{i}$. With this specification, if we assume that each commodity accounts for a relatively small share of total land use, the elasticity of supply is simply equal to the elasticity of transformation $\rho$.

Comparing the baseline to a new counterfactual equilibrium, we find that the changes in production, costs and income are given by:

$$
\begin{aligned}
{\widehat{Y_{i g}}} & ={\widehat{C_{i g}}}^{1+\rho}{\widehat{\Phi_{i}}}^{-\rho} \\
\widehat{\Phi}_{i}^{1+\rho} & =\sum_{g} \pi_{i g}^{T}{\widehat{C_{i g}}}^{1+\rho} \\
\widehat{\Phi}_{i} & =\sum_{g} \pi_{i g}^{T}{\widehat{Y_{i g}}}^{1+\rho}
\end{aligned}
$$

As with the baseline case, it is possible to obtain a closed-form solution for the gains from trade when the elasticity of substitution between commodities (in the CES production function of final goods) is equal to the elasticity of substitution between final goods in preferences:

$$
G T_{i}=\left\{e_{i, L} \Lambda_{i}^{\frac{1-\sigma}{\sigma}}+e_{i, R}\left[\sum_{g} \pi_{i g}^{T}\left(\lambda_{i g}^{C-\frac{1-\sigma}{\theta g}} \frac{D_{i g}^{C}}{Y_{i g}^{C}} \sum_{k} d_{i k g} \lambda_{i k}^{F^{-}-\frac{1-\sigma}{\theta_{k}}} \frac{D_{i k}^{F}}{Y_{i k}^{F}}\right)^{\frac{1+\rho}{\rho+\sigma}}\right\}^{\frac{\rho+\sigma}{\sigma(1+\rho)}}\right\}^{\frac{\sigma}{1-\sigma}}
$$

where $\Lambda_{i}$ is defined by (34) as in the baseline specification. This expression is very close to equation (35) for the baseline model when the exponent $\frac{\rho+\sigma}{\sigma(1+\rho)}$ is close to one (details in the Appendix).

\section{Calibration of the model}

In this section, we describe how our data can be used to calibrate the model in order to compute the gains from trade and other counterfactuals.

Commodity production and trade. We use our production and trade data at the commodity level to directly calibrate production values $Y_{i g}^{C}$, demand $D_{i g}^{C}$, and import shares $\lambda_{n i g}^{C}$. Demand $D_{n g}^{C}$ is calibrated as $D_{n g}^{C} \equiv \sum_{i} X_{n i g}^{C}$ (the sum of import values), where $X_{i i g}^{C}$, or internal trade flows, are defined by $X_{i i g}^{C} \equiv Y_{i g}^{C}-\sum_{n \neq i} X_{n i g}^{C}$ (production - exports), if this is nonnegative, and zero otherwise 
(zeros are further discussed in Section 4.1). To ensure that trade, production and consumption are all harmonized, we use a slightly more aggregated classification than we do for most stylized facts. Table 6 in the Appendix provides the full list of commodities in our calibration. ${ }^{21}$

Downstream industries. We combine our commodity data with information on secondary industries across broad sectors: production $Y_{i k}^{F}$, demand $D_{i k}^{F}$, trade shares $\lambda_{\text {nik }}^{F}$, expenditure shares $\alpha_{n k}$ as well as end use shares $d_{i g k}$, i.e. the share of commodity $g$ output used in manufacturing industry $k$. Here, we compare two strategies to construct commodity-industry linkages.

Focusing on the year 2007, we use GTAP data to obtain harmonized cross-country production and consumption data across 29 downstream manufacturing sectors. We also use GTAP data to provide usage information for agricultural products and fuels by downstream industries (when GTAP commodity sectors are more aggregated we associate downstream industries on a proportional basis). For minerals, we use data from the USGS to obtain end uses for each finely-defined commodity by NAICS 3-digit purchasing industry, which we match with the GTAP industrial classification. $^{22}$ This combination of GTAP and USGS data provide $d_{i g k}$, which we then use to construct the direct use coefficients $\varphi_{i k, g}=d_{i g k} D_{i g}^{C} / Y_{i k}^{F}$, i.e. the value of commodities $g$ used to produce one dollar of output in industry $k$ in the baseline equilibrium. The share of labor is simply $\varphi_{i k, L}=1-\sum_{g} \varphi_{i k, g}$.

As a robustness check, a more simple alternative is to assume that there are two downstream industries: manufacturing and services, the latter of which does not use commodities. We then calibrate production in each sector to match overall GDP (adjusted for value-added in primary sectors) and the share of services provided in the World Bank online data.

Natural resource intensity. Next, we calibrate the share of natural resources in the production costs of each commodity as well as the share of natural resources in total income. GTAP data provide information on the share of land and natural resources in the production costs of commodities for each country across broadly defined industries (see Table 4 for summary statistics). We then assume that resource uses are identical across commodities within each GTAP sector and country.

An alternative option that does not rely on GTAP data, and can be implemented for other years, is to assume that the share $\varphi_{i g, R}$ of natural resources in production costs is constant and equals $\varphi_{i R}$ across all commodities within a country $i$. We would then calibrate $\varphi_{i R}$ such that the total share of income from natural resources, $e_{i R}^{t o t}=\sum_{g} e_{i g}$, matches the aggregate natural income share values

21. Each commodity $g$ corresponds to a 4-digit or 6-digit Harmonized System category, with a few exceptions. Aggregation is discussed in the data appendix, and we post on our website the exact mapping with 6-digit HS codes.

22. The USGS provides end uses for each mineral across US manufacturing industries. For other countries, we reallocate the use of each commodity $g$ across industries $k$ (that appear in the US end-use data) proportionally to output $Y_{i k}^{F}$ of each industry $k$ in that country. 
provided by the World Bank. In this case, the resource intensity is given by: $\varphi_{i R}=e_{i R}^{t o t} E_{i} / \sum_{g} Y_{i g}^{C}$, where $Y_{i g}^{C}$ denotes commodity production, and $E_{i}$ denotes GDP. These shares are between 30 and $45 \%$ for most countries, and usually close to the ones obtained with our baseline strategy.

Elasticities. Last, we need to calibrate the model parameters $\theta_{k}$ (trade elasticity for downstream sectors), $\theta_{g}$ (trade elasticity for commodities), $\eta_{k}$ (elasticity of substitution between labor and commodities in the downstream sectors), $\rho_{g}$ (elasticity of substitution between labor and natural resources in the upstream sectors) and $\sigma$.

We follow Simonovska and Waugh (2014) and other papers estimating trade elasticities and assign $\theta_{k}=5$ for downstream industries. As discussed in Fact 4 and Table 3, commodities do not seem to have significantly higher trade elasticities, hence we set $\theta_{g}=5$ for commodities in our baseline calibration. We also explore alternative value choices where we quadruple the trade elasticity to $\theta_{g}=20$ for all primary commodities, keeping $\theta_{k}=5$ for downstream industries.

More important are the demand and supply elasticities, which are determined by $\eta_{k}$ and $\rho_{g}$ in our model. We use a value of 0.4 for both $\eta_{k}$ and $\rho_{g}$, which generate price elasticities of demand close to 0.4 and price elasticities of supply close to 0.6 (see equation 10 with $\frac{\varphi_{i g, L}}{\varphi_{i g, R}} \approx 1.5$ ). This is a conservative choice. As documented in Table 1 and Appendix Figures 6, 14(a) and 14(b), this is above a majority of elasticity estimates in the literature. We will also examine alternative value choices to illustrate the role of these elasticities.

When considering counterfactuals such as movements back to autarky, the most relevant elasticities of demand and supply will be long-run elasticities, rather than short-run elasticities, which compose the majority of our surveyed estimates. Although in Appendix Table 6 we note that most estimated long-run elasticities still tend to be less than unity in absolute value, the literature is relatively scarcer for long run elasticity estimates. The ideal long-run elasticity estimates would account for the role of technological innovation and resource discoveries; our aim is not to take a stand on the "true" long run elasticity, but rather demonstrate the potential magnitudes of the gains from trade assuming reasonably inelastic long-run demand and supply. In contrast, when considering intermediate trade cost trade changes or supply shocks, short run elasticities are likely more relevant.

The elasticity of substitution between the output of industries $k$ in final demand plays a less central role. In the baseline model, we assume $\sigma=1$ (Cobb-Douglas) as is standard in recent trade models (Caliendo and Parro 2015). In alternative calibrations, we specify $\sigma=0.4$ as for other elasticities of substitution (this value is close to the panel estimates of Comin et al. 2015), which allows us to obtain closed form solutions for the gains from trade relative to autarky (Proposition 1). 


\subsection{Treatment of zeros in counterfactuals simulating autarky}

At this level of aggregation, all countries (except the US) have at least one commodity with positive demand but no domestic production. In counterfactuals that consider only partial trade cost changes, each country will still be able to import commodities to satiate its demand at a (potentially) higher price. However, when considering a full movement back to autarky, the price of a commodity that is not produced domestically will be infinite in autarky if the elasticity of substitution with labor or other commodities is strictly smaller than unity. The aggregate gains from trade will also be infinite in that case, as we can see for instance in equation 35 of Proposition 1 with $\sigma<1$. Motivated by various estimates indicating that even long-run elasticities are likely to be smaller than unity in the current economy, we obtain that gains from trade are infinite unless:

i) zeros are measurement errors, not true zeros;

ii) elasticities of substitution are not constant and increase as we go to autarky.

We explore two venues that account for these possibilities. The first case is an empirical issue, and a relevant one given the scarcity of commodity production data. We propose using gravity equations to fill in (most) missing values using predicted internal trade in these cases. The second issue we can address using the alternative version of the model with choke prices.

i) Using gravity equations to infer missing production A potential concern with trade and production data at this level of granularity is that they are somewhat noisy, and subject to measurement errors. For instance, we find many cases where a country exports a commodity that it does not have production of in our data, although some of this may be due to re-exporting. ${ }^{23}$

To address some of these concerns, we attempt to predict internal flows using gravity equations. We propose a method that relies on key properties of the Poisson pseudo maximum-likelihood (PPML) estimator. The first step is to estimate the following equation for trade flows for each commodity $g$, allowing for a country-specific border effect $\beta_{\text {HomeBias,ng: }}$ :

$$
\begin{aligned}
\log X_{\text {nig }}= & F X_{i g}+F M_{n g}+\beta_{\text {Dist }, g} \log \text { Dist }_{n i}+\beta_{\text {Contig }, g \text { Contig }_{n i}} \\
& +\beta_{\text {Lang, }, g} \text { CommonLang }_{n i}+\beta_{\text {Colony }, g} \text { Colony }_{n i}+\beta_{\text {HomeBias }, n, g} \mathbb{I}(n=i)+\varepsilon_{\text {nig }},
\end{aligned}
$$

Given the presence of exporter, importer and exporter-specific border effects, fitted values for total exports, total production, total expenditures - and therefore also internal flows - will be automatically equal to observed values (Fally 2015). Exporter and importer fixed effects can be identified, even if there are missing internal flow data $\log X_{n n g}$. However, with such missing values, the home bias coefficient cannot be identified (see Appendix for more details).

23. Another indication of measurement issues is that different publications provide different statistics. For instance, various mining trade publications provide slightly more comprehensive, although similar, production statistics. 
To compute the home bias coefficient for missing internal flows, we employ GTAP data at a more aggregated level, which features much fewer zero internal flows, assuming that a countryspecific border effect is common across commodities $g$ within each GTAP industry category $G$. To compute a given value of $\hat{\beta}_{\text {HomeBias }, i G}$, we use equation 46 to predict internal flows and then calibrate $\hat{\beta}_{\text {HomeBias }, i G}$ such that we match internal flows in GTAP at the aggregate level. Using this coefficient along with those of estimated equation 46, we can predict internal flows. The idea underlying this is as follows: if a country is missing production values for oranges, then the production and consumption of that country at the aggregate industry level (the GTAP industry "vegetables and fruit") is informative about the relative size of internal flows. In turn, gravity equations at the commodity level inform us about the patterns of comparative advantage within this aggregate industry, which helps us determine relative production volumes across commodities.

This approach is remarkably efficient in reducing the number of zeros in production across countries and commodities. The number of zeros is reduced by $72 \%$ if we take a raw count, and reduced by $98 \%$ if we weight zeros by the value of imports for that country and commodity. For remaining cases, accounting for just $2 \%$ of imports with missing production, we exclude them from our calculations by normalizing demand to zero at the country and commodity level. ${ }^{24}$

ii) Model with choke prices The difficulty in using the alternative specification in choke prices is where to set the cutoff at which demand for each commodity goes to zero, a phenomenon with little historical precedent. Although this is an inherently difficult parameter to infer, there are reasons to believe that a choke price would be quite large compared to current prices. In equation 39 , when choke prices become closer to the current price (that is, when $\Delta_{i g} \rightarrow 1$ ), demand for a given commodity becomes infinitely elastic. However, as we survey in Appendix Table 6, estimated price elasticities of demand for a variety of commodities across different countries and time periods are all rather low, whether in the short or long run. Further, the relatively high volatility of commodity prices relative to wages is well explained by low price elasticities of demand for such inputs (Cafiero et al. 2011).

\section{Counterfactual simulations}

We can now solve for equations (14)-(25) to simulate partial trade costs changes and equations (14), (15), (22)-(25) and (30)-(31) to simulate full autarky. We explore various counterfactuals to illustrate the role of commodities:

24. We do so also for tiny values of internal flows leading to $\lambda_{n g}<0.01$. Our results are robust to alternative censoring or winsorizing treatments. 
- Gains from trade relative to autarky: Our first but most speculative counterfactual is to simulate a full movement back to autarky. Even if autarky is highly hypothetical, it is a useful benchmark to compare to the literature (e.g. Costinot and Rodríguez-Clare 2014). The main point is to show that commodities can rationalize much larger gains from trade relative to more standard models. We also use the comparison to autarky to describe the gains from trade across factors of production and the role of the different elasticities.

- Intermediate changes in trade costs: We simulate more modest changes in trade costs to examine whether commodities are relatively less important for smaller changes in trade costs.

- Tariffs: We examine the extent to which the role of commodities and natural resources is muted or magnified when we consider the introduction of tariffs. In particular, as demand and supply are less elastic for commodities, the deadweight loss from tariffs may differ from more standard models without commodities.

- Export taxes: We also examine to what extent initial distortions may affect our estimates of the gains from trade. To do so, we recompute the gains relative to autarky by assuming that commodity exporters initially charge optimal export taxes (or equivalently optimal markups if there is a single producer in each country exploiting its market power, such as De Beers for South African diamond production).

- Critical suppliers: To illustrate the role of the geographic concentration of resources and production, we explore counterfactuals where we shut down trade of a given commodity only for the top exporter, and examine how this shock affects prices and costs in other countries. We highlight the particular role of China, the top exporter of many commodities.

\subsection{Gains from trade relative to autarky}

Aggregate gains from trade There are multiple ways to illustrate the gains from trade in our model relative to more standard models. First we compare to a model where labor is the only input to the commodity production process, which is essentially equivalent to allowing for a much more elastic supply of commodities, since labor (unlike resources) is freely mobile across sectors. In Figure 3, we show the aggregate gains from trade for each country, with log gains in our baseline calibration on the vertical axis, compared to a model that uses only labor, with its predicted $\log$ gains on the horizontal axis. We find that the use of natural resources in the production process yields much larger gains from trade; all outcomes are above the 45-degree line.

We also compute the gains from trade in our model relative to a model that only has final goods as possible products (and only labor as input). Appendix Figure 21 shows that we obtain similar 


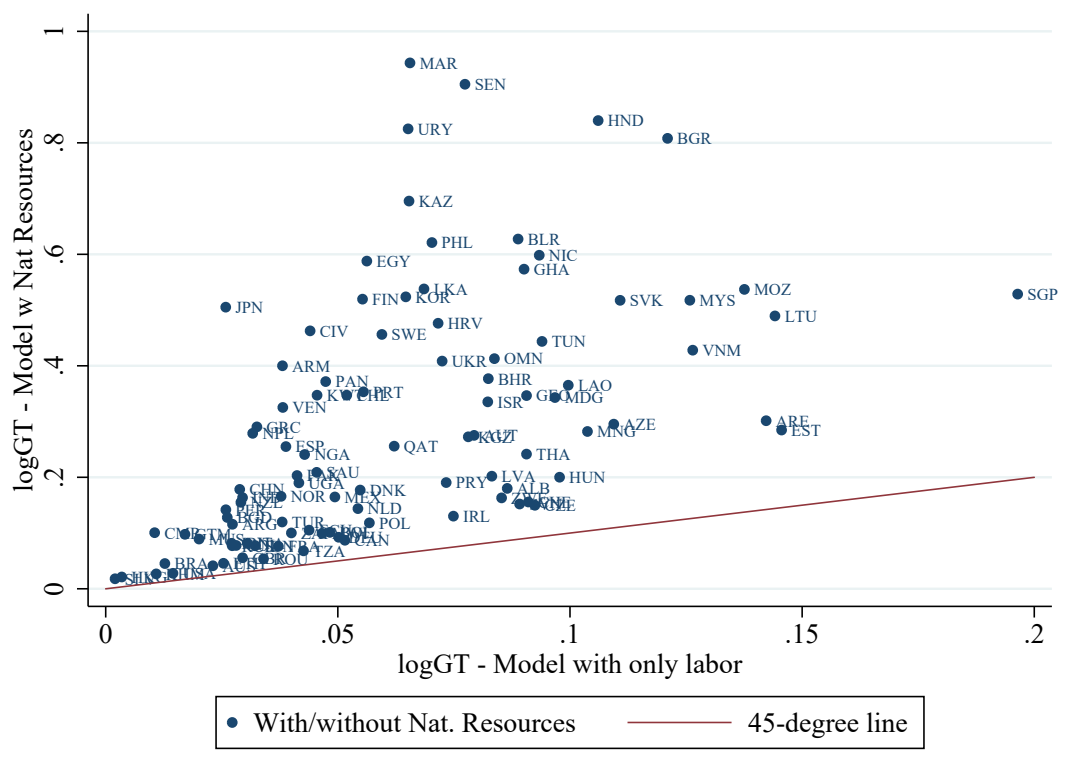

Figure 3: Gains from trade relative to model with only labor

results to those in Figure 3: the difference between the two models is now even slightly larger, since trade in final goods alone yields smaller benefits.

In these results, we use the method described in section 4.1i) to infer production using gravity equations, which limits the number of cases in which countries have positive demand for a commodity but no production, leading to potentially infinite gains from trade. However, an alternative is simply to set demand to zero in all cases in which domestic consumption of a commodity $g$ is less than $0.01\left(\lambda_{n g}<0.01\right)$. In Appendix Figure 22, we replicate the results of Figure 3 (comparing the aggregate gains from trade in our baseline model to one without natural resources) using gravity adjusted trade flows, and find similar results with only slightly smaller gains from trade.

With choke prices Very large gains from trade arise when prices are very high for at least some commodities. One may be worried that in those cases, an economy would be able to find substitutes to that commodity. Such substitution would lead to a choke price, i.e. a price upper bound above which demand for that commodity would drop to zero. In Section 3.4.1, we describe one way to account for such choke price. To calibrate such model, one needs to know the value of $\Delta_{i g}$ capturing the ratio of the current price relative to the choke price. To illustrate the sensitivity of our results to the presence of choke prices, we provide alternative counterfactual simulations with values $\Delta_{i g}=0.05,0.1$ and 0.2 respectively, which correspond to choke prices being roughly 1800 , 316 , and 56 times higher than the current price, respectively, with $\eta_{k}=0.4$. Results are depicted in Figure 4. In spite of the presence of a choke price, we find that the gains from trade are still much 


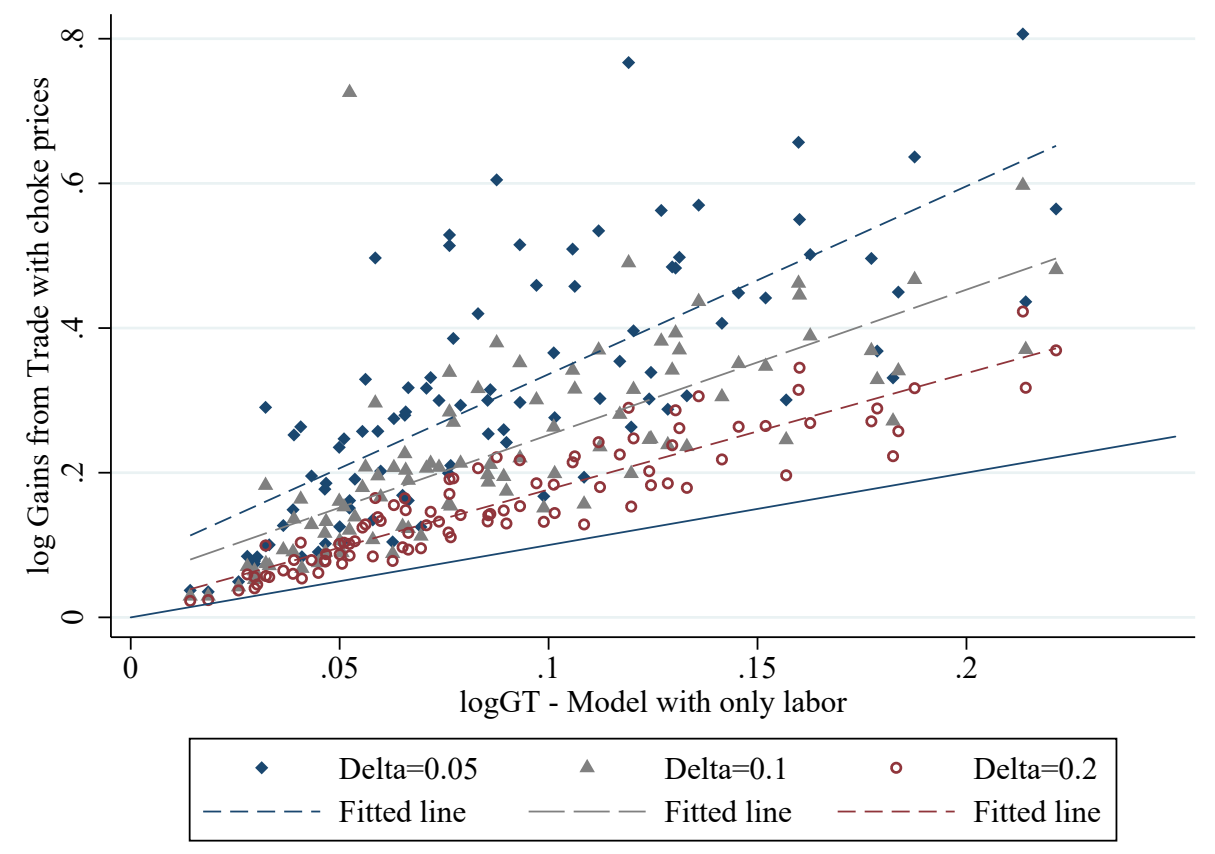

Figure 4: Gains from trade with choke prices

larger than in the case without natural resources (and without choke prices). Of course, higher values of $\Delta_{i g}$ - corresponding to lower choke prices - lead to smaller gains from trade.

As we do not have reliable estimates of choke prices, we return to the previous approach to provide additional results on gains from trade, e.g. on gains from trade across factors of production and the role of elasticities. The same results hold qualitatively if we instead specify a choke price.

Heterogeneous gains from trade Figure 5 compares the gains from trade for workers and natural resources relative to the aggregate gains from trade. First, we can see that workers fare better in our model as a country opens to trade. Most points are above the 45-degree line: worker welfare gains (on the y-axis) are almost always larger than aggregate gains in each economy (x-axis). This indicates that the share of labor wages in total income tends to increase with trade and that, on aggregate, the relative price of commodities tends to decrease.

The consequences of trade for natural resource owners is however highly heterogeneous. On the same figure, we plot the average log gains from trade (weighted by initial income share) for owners of natural resources. As we can see, gains for resource owners have a high variance across countries. We also confirm that, within countries, there is a high variance in the gains from trade across types of resources, with big winners for instance in Russia, Norway, Saudi Arabia among other resource-rich countries. We further show in Appendix (Figure 23) how resource owners fare relative to autarky depending on whether the commodity using these resources tends to be exported 


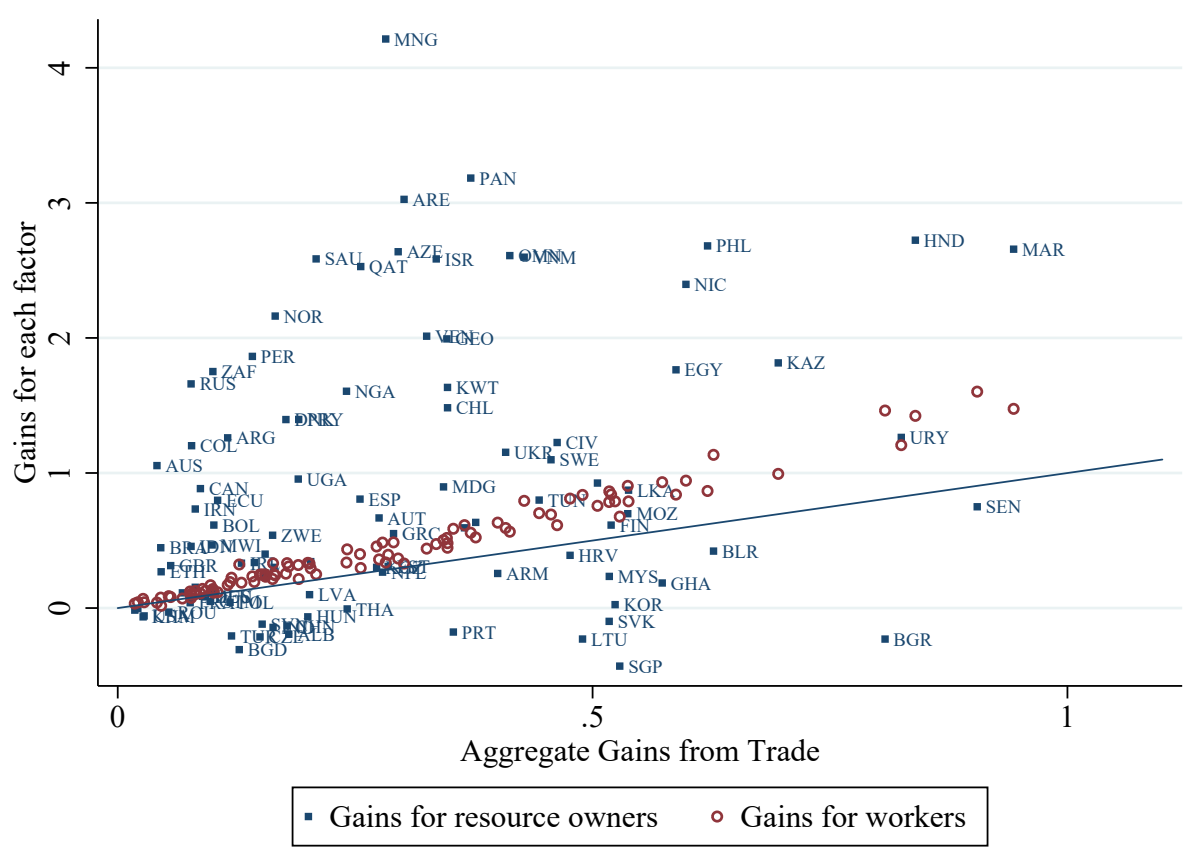

Figure 5: Heterogeneous gains from trade

or imported (on net). The intuition is in line with specific-factor models, as owners of resources used for commodities that are imported tend to lose from trade, while others tend to gain.

Role of supply and demand elasticities. As noted in the theory section, the gains from trade in primary commodities depend on supply and demand elasticities. To illustrate the role of these elasticities, we solve for a counterfactual autarky equilibrium using alternative values of demand and supply elasticities. In our baseline calibration, we assume that the elasticities of substitution $\eta_{k}$ and $\rho_{g}$ are equal to 0.4 (leading to price elasticities of demand and supply equal to 0.4 and 0.6 respectively). In Figure 6, we examine the gains from trade for our model if we assume $\eta_{k}=\rho_{g}=0.95$, i.e. almost Cobb-Douglas. For each set of elasticities, we compare our results to a model with a single factor (labor). We plot log gains from trade for each country on the vertical axis while we plot gains from trade from the single-factor model on the horizontal axis. When we assume higher elasticities of substitution, the gains from trade decrease quickly. For elasticities close to unity, the gains from trade are fairly similar to the single-factor model (45-degree line). In Appendix Figure 24, we further explore the sensitivity to alternate values of elasticities. Higher elasticities that remain below unity ( 0.6 for demand and 0.9 for supply) yield smaller gains from trade than our baseline specification, but still a notable difference from the single-factor model. For elasticities larger than unity, the gains from trade are essentially identical to the single-factor model and are considerably smaller than in our baseline model. 


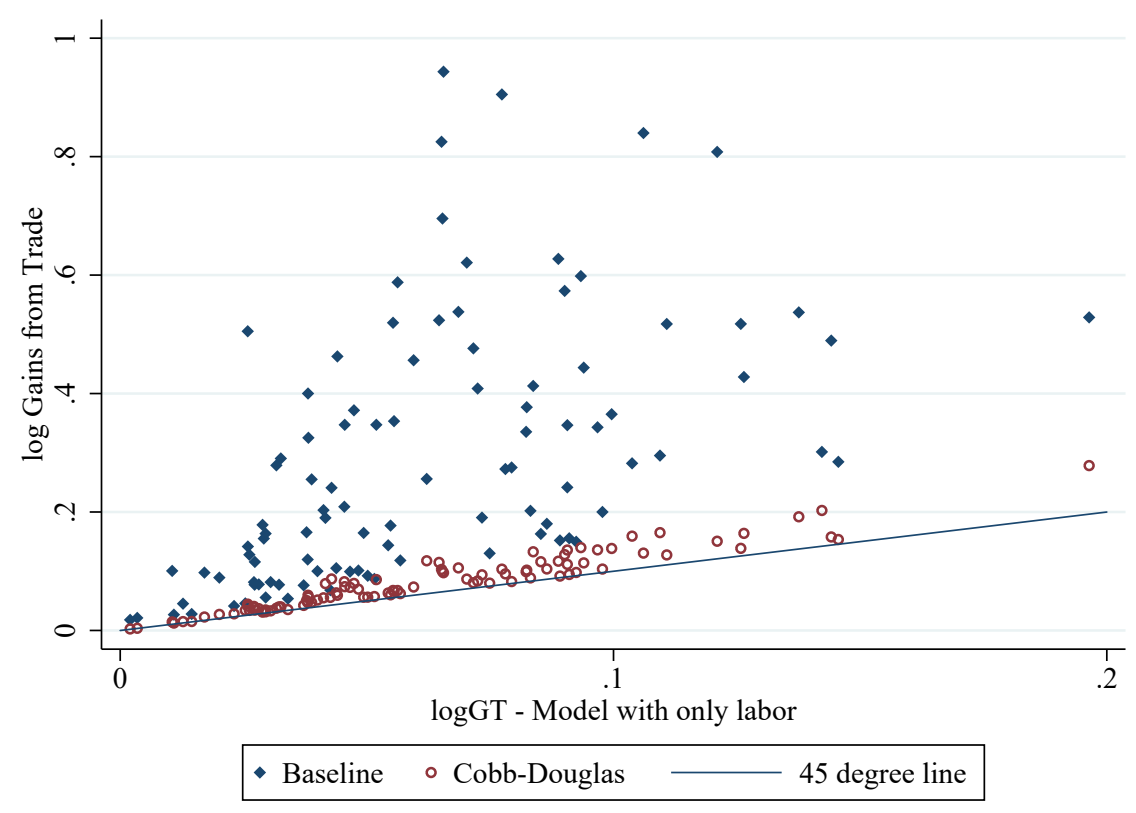

Figure 6: Gains from Trade (Aggregate) for Different Elasticities of Substitution

The gains from trade for resource owners are highly heterogeneous and often large, as discussed previously in Figure 5. Interestingly, gains from trade for natural resource owners are smaller and less dispersed when elasticities of substitution are higher as we illustrate in Figure 25. Intuitively, the role of natural resources and commodities is muted in that case.

While the results above highlight the role of the supply and demand elasticities for commodities, one can notice that the gains from trade are large in spite of relatively higher elasticities of substitution between final goods in consumer preferences ( $\sigma=1$ in the baseline specification). This implies that the elasticity of substitution across final goods is not as crucial but its role is not negligible. If a commodity becomes prohibitively expensive, substitution with final goods that do not rely on this commodity alleviates the loss from autarky. Indeed, we obtain even larger gains from trade, especially for small countries, when we specify a lower elasticity of substitution between final goods - see Figure 8 below and Figure 26 in Appendix with $\sigma=0.4$.

Covariates Next, we investigate how country characteristics correlate with the gains from trade in our model in Figure 7. As is well known, in most models, smaller countries tend to gain more from trade. As depicted in panel (a), we find that the negative correlation between gains from trade and market size is even starker (more negative) when we account for commodities and natural resources. The intuition is simple. Smaller countries tend to have less diverse natural resources and when they open to trade, specialize in the production of only a few commodities and gain 
Figure 7: Determinants of the gains from trade, compared with labor-only model

(a) Gains from Trade and Market Size

Baseline model:

$\log G T_{i}=4.286^{* * *} \cdot \log E_{i}+c s t$.

Single-factor model:

$\log G T_{i}=0.836^{* * *} \cdot \log E_{i}+c s t$.

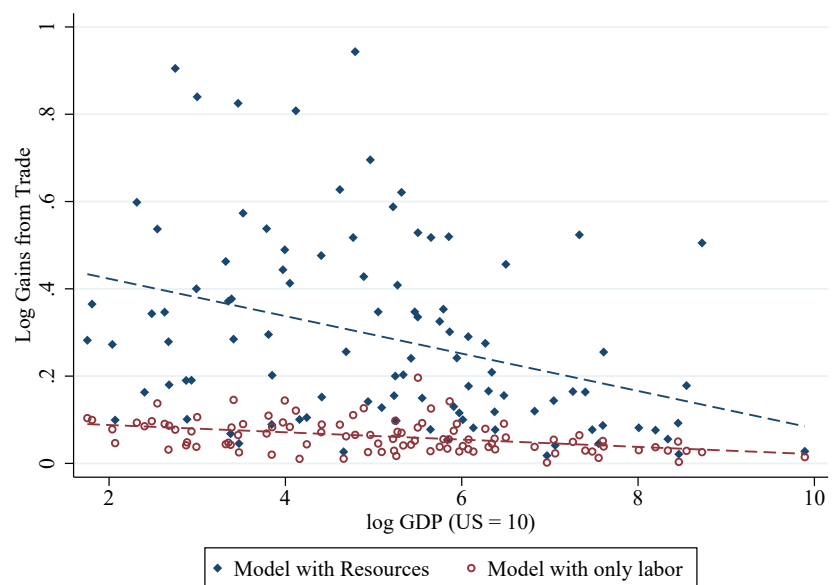

(b) Gains from Trade and Per Capita Income

Baseline model:

$\log G T_{i}=-1.706 \cdot \log y_{i}+$ cst .

Single-factor model:

$\log G T_{i}=0.175 . \log y_{i}+c s t$.

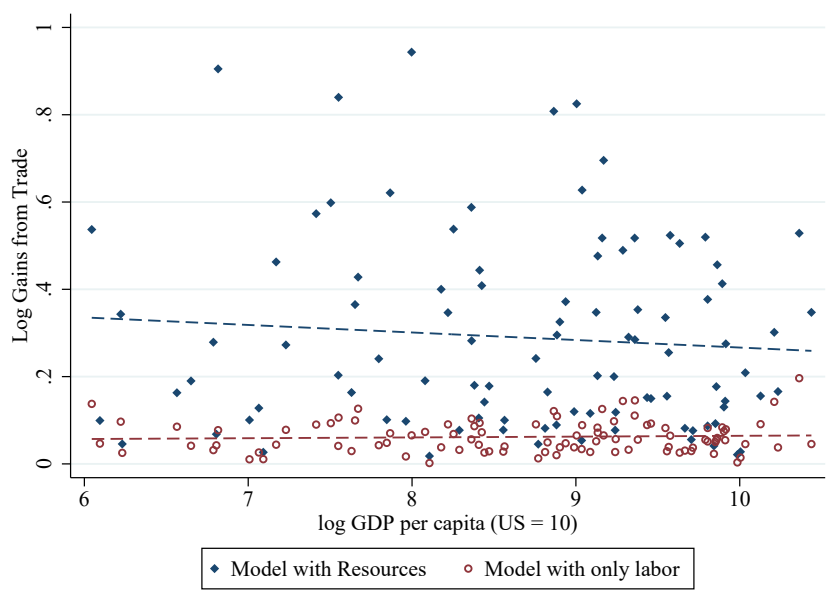

access to various other commodities that cannot be produced domestically. ${ }^{25}$

Second, as documented in panel (b) of Figure 7, we find a more negative (although not statistically significant) relationship between the gains from trade and per capita income across countries. In comparison, this correlation is positive (though insignificant) in a standard model with only labor, where natural resources do not play a role. With commodities, the negative correlation with per capita income is partly driven by the fact that poorer countries also tend to have a smaller market size (in terms of GDP).

We also examine other country characteristics, such as the share of natural resource income in GDP, but find no significant relationship or change relative to more standard models.

25. We also find a stronger (negative) correlation with country size in terms of land area. 


\subsection{Sensitivity to alternative specifications}

Trade elasticity. The trade elasticity for commodities plays a more muted role in explaining the gains from trade, unlike in standard models where the gains from trade (in log) are proportional to the trade elasticity. As shown in Figure 8 for a selection of countries and Appendix Figure 27 for all countries, a higher elasticity of $\theta_{g}=20$ for commodities leads to only slightly lower gains from trade in comparison to $\theta_{g}=5$. Contrary to the standard formula for the gains from trade (Arkolakis et al. 2012), in this context a doubling of the trade elasticity for commodities would not cut the (log) gains in half: the gains from trade in our model still largely exceed the gains from trade without natural resources (still three times larger for the median country).

Model of land allocation In Section 3.4.2, we consider an alternative model of commodity production with a single factor of production (land) that can be allocated to producing different commodities with a constant elasticity of transformation (CET). This version is also isomorphic to a Roy model of land allocation with a continuum of parcels with i.i.d. productivity draws (from a Frechet distribution) associated with each commodity (as in Galle et al. 2017). We calibrate this model using the same production and trade data and the same parameter values for $\rho=0.4$ (and $\eta=0.4$ ) as in the baseline model. As shown in Figure 8 (and Appendix Figure 29(a) for all countries), the gains from trade are still large - actually larger than in the baseline model.

Types of commodities Are the large gains from trade with commodities driven by specific groups of commodities? We examine the robustness of our results by replacing natural resources (fixed factors) by labor for certain groups of commodities: either fuels, minerals or agricultural products. Results shown with the hollow symbols in Figure 8 (and Appendix Figure 30 for all countries) indicate that broadly our findings are not driven by a few specific commodities (e.g. oil). On average, we obtain large gains from trade even when we "remove" a broad type of commodity, i.e. shutting down the role of natural resources for either fuels, minerals or agriculture.

Aggregation of downstream sectors In Figure 29(b), we compare the gains from trade from our baseline model with services and multiple downstream sectors to a model with services but only one downstream sector, manufacturing. We find that the gains from trade are larger with only one manufacturing sector. The main reason is that in our baseline model consumers can better substitute between final goods (e.g. cars vs. plastic products) when either one lacks a key commodity and thus becomes prohibitively expensive. In the baseline model, the upper tier of consumption is Cobb-Douglas across final goods, whereas in the one-sector model, the final good requires all commodities and has no substitutes. 


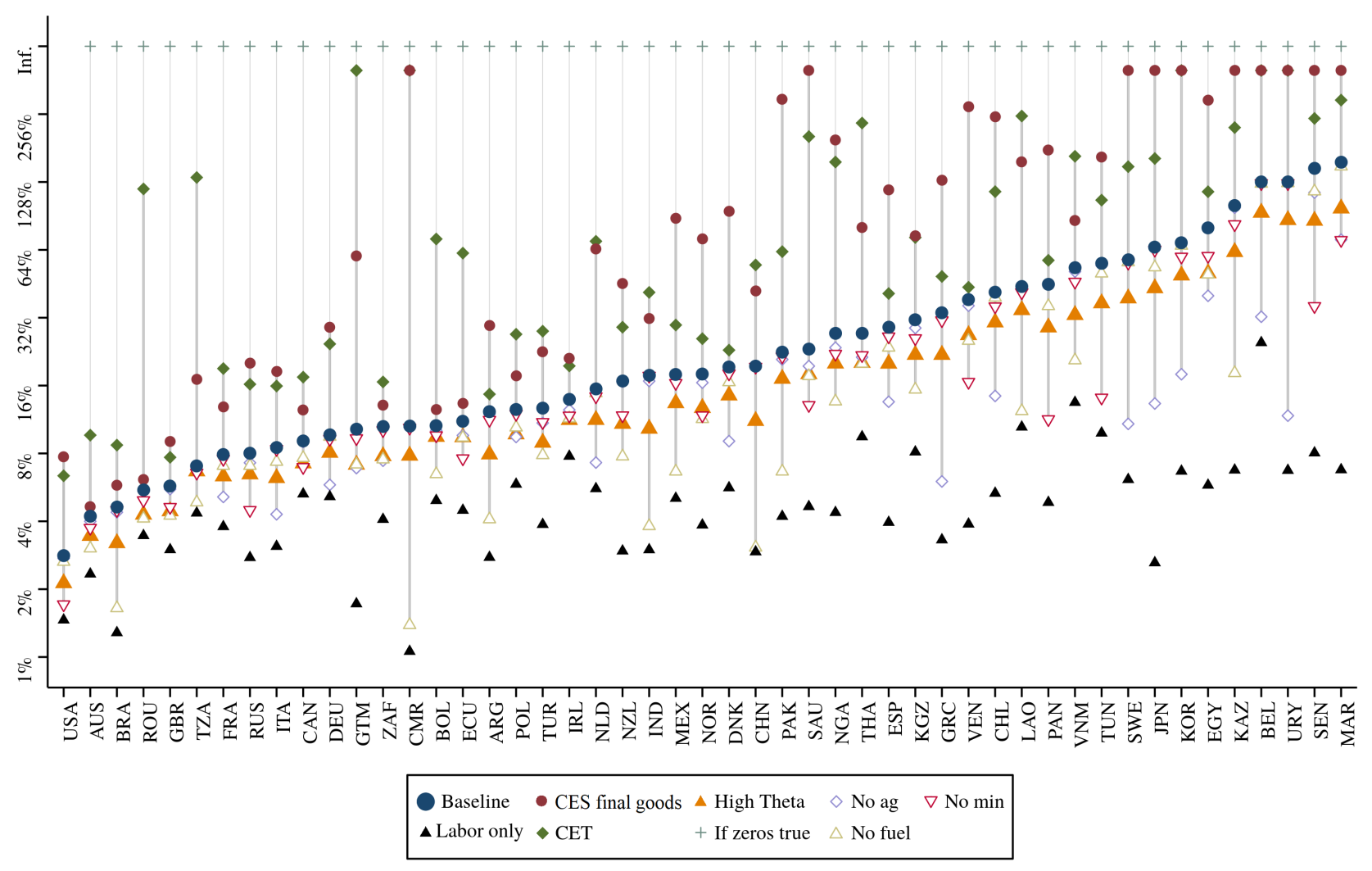

Figure 8: Gains from trade across different specifications (\% GT, truncated at 400\%)

A third point of comparison would be to have preferences with a lower elasticity of substitution $\sigma$ between multiple final goods. If we set $\sigma=0.4$ (which we refer to as "CES final goods" in Figure 8) instead of unity (Cobb-Douglas), we find that the gains from trade are actually larger than both the Cobb-Douglas and the single-industry specifications.

A more conservative commodity classification. As a robustness check, we can use an alternative classification table which is potentially more conservative than the correspondence table that we use for most of our counterfactuals. To construct a potentially more conservative table, we only use less refined mineral commodity production and trade data accounting for $14.3 \%$ of total trade in 2007 (the baseline data accounts for $20.2 \%$ of trade that year). For instance, in the baseline classification, we aggregate the value of mined and smelted copper, whereas in our conservative correspondence, we only consider mined copper (for more details, the full correspondences are provided online for both classifications). We compute the gains from trade relative to using only labor to produce commodities using this conservative classification in Appendix Figure 28, and find similar, only marginally smaller, gains from trade relative to our baseline. 


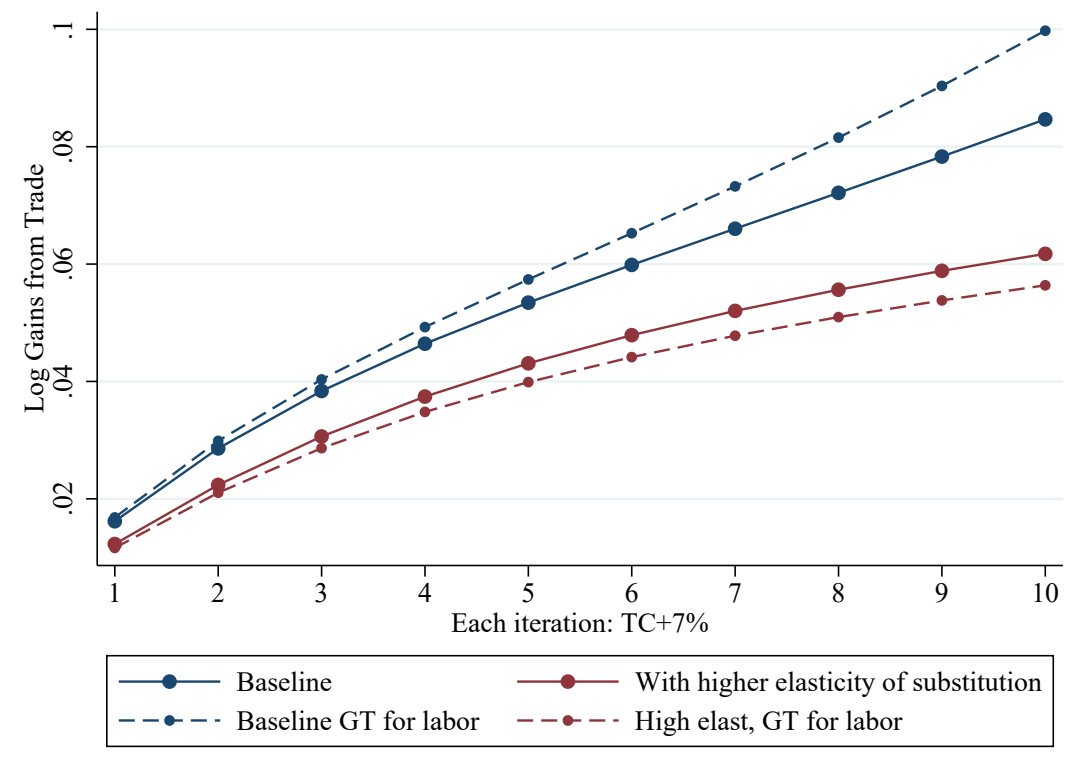

Figure 9: Gains from trade - increasing trade costs by $10 \%$ at each iteration

Aggregation of commodities One of the key issues that we wish to highlight is the importance of examining detailed data by commodity. If we were to only use aggregate data for primary production (e.g. aggregating all minerals), we would miss much of the gains from trade and specialization. We illustrate this point in Figure 31 in the Appendix, where we compare the gains from trade in our baseline model to one where all primary commodities are pooled into one single commodity sector. We find that imputed gains from trade are much smaller when commodities are aggregated into a single sector, close to what we find in a model without commodities.

Other years If downstream sectors are aggregated and detailed downstream sector data from GTAP are not used, we can calibrate the model for other years than 2007. In Figure 32 in the Appendix we calibrate the gains from trade in a model with 1995-2013 commodity production data in the single-downstream-sector model. For all years, we find that the gains from trade are much larger than in a more standard model without natural resources - hence 2007 is not an exception. In both versions of the model, gains from trade increase over time (since the baseline economy is increasingly open) and the differences between the two specifications are fairly constant.

\subsection{Partial trade cost changes}

Instead of comparing with autarky, the next counterfactuals examine more realistic partial changes in trade costs. Since commodities face a low elasticity of demand (are difficult to substitute) but account for only a modest share of world trade, the effects of trade costs are very non-linear. The 


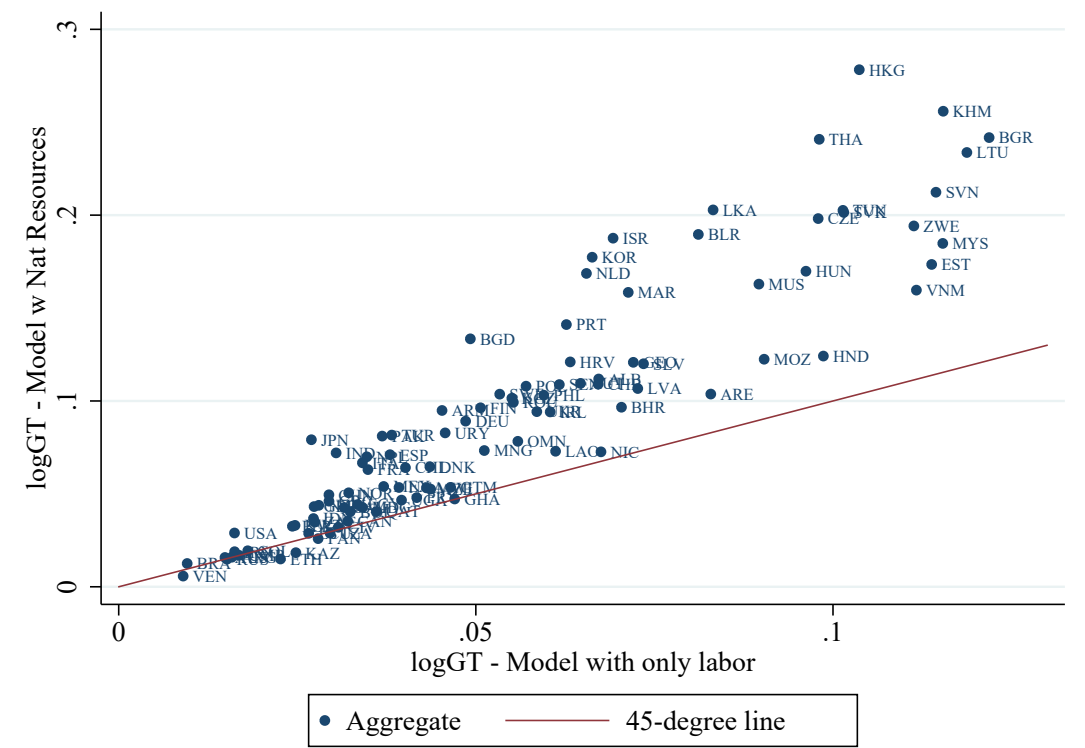

Figure 10: Gains from trade across countries - intermediate changes in trade costs

elasticity of substitution does not matter as much when changes in trade costs are small (i.e. the Arkolakis et al. 2012 formula provides a good approximation), but a sizable difference appears when trade costs changes become larger as seen in Figure 9. In this figure, we increase trade costs increase by $10 \%$ in each iteration. After ten iterations, median welfare losses (in log) are about $30 \%$ larger with low elasticities of substitution. If we focus on labor, the standard model no longer provides a good approximation of the gains from trade. Even for small changes in trade costs (dash lines in Figure 9), the gains from trade for labor in a model with primary commodities are about $50 \%$ larger (for the median country) than in standard models with higher substitution or no natural resources. We document the heterogeneity across countries in Figure 10.

\subsection{With distortions: tariffs and export taxes}

Tariffs Rather than changes in trade costs, one may be interested in changes in tariffs and tariff revenues generated by trade in commodities. With particularly low demand and supply elasticities, we can expect smaller deadweight losses and thus much smaller welfare losses compared with changes in trade costs.

Several equations describing equilibrium and counterfactual changes need to be adjusted. With import tariffs $t_{n g}$ and $t_{n k}$ on commodities $g$ and industries $k$, the changes in trade costs are: $\widehat{\tau_{\text {nik }}}=1+t_{\text {nik }}$ and $\widehat{\tau_{\text {nig }}}=1+t_{\text {nig. }}$. Income should now include tariff revenues, given by: 


$$
T_{n}=\sum_{i, k} \frac{t_{\text {nik }}}{1+t_{\text {nik }}} X_{\text {nik }}+\sum_{i, g} \frac{t_{\text {nig }}}{1+t_{\text {nig }}} X_{\text {nig }}
$$

and sales are now equal to: $Y_{i g}^{C}=\sum_{n}\left(C_{i g} \tau_{n i g}\right)^{-\theta_{g}}\left(1+t_{n g}\right)^{-1-\theta_{g}} P_{n g}^{\theta_{g}} D_{n g}$, with a similar expression for sales in industry $k$. Notice the -1 added to the trade elasticity in the exponent, since only a share $1 /\left(1+t_{n g}\right)$ of the value of trade flows is earned by country $i$.

The equation describing counterfactual changes in income is now:

$$
\widehat{E}_{i}=e_{i L} \hat{w}_{i}+\sum_{g} e_{i g, R} \hat{r}_{i g}+\sum_{g} \frac{t_{n g} M_{n g}}{D_{n g} E_{n}} \sum_{i} \lambda_{n i g}^{C} \widehat{X}_{n i g}+\sum_{k} \frac{t_{n k} M_{n k}}{D_{n k} E_{n}} \sum_{i} \lambda_{n i k}^{C} \widehat{X}_{n i k}
$$

where the last two terms capture additional revenues from import tariffs. Changes in output are then given by:

$$
\widehat{Y C}_{i g}=\sum_{n}\left(1+t_{n g}\right)^{-1-\theta_{g}} \pi_{n i g}^{C}\left(\widehat{C}_{i g}\right)^{-\theta_{g}}\left(\widehat{P C}_{n g}\right)^{\theta_{g}} \widehat{D_{n g}},
$$

with a similar expression for industry $k$.

We simulate a $100 \%$ worldwide increase in tariffs in $10 \%$ increments, and illustrate the results in Figure 11. Once tariff revenues are accounted for, one can see in Figure 11 that there is almost no difference in aggregate welfare losses between the baseline model and a more standard model without natural resources. Implications for labor income are less negligible, as shown with difference between the two dash lines, indicating slightly larger effects on redistribution of welfare across factors of production within countries.

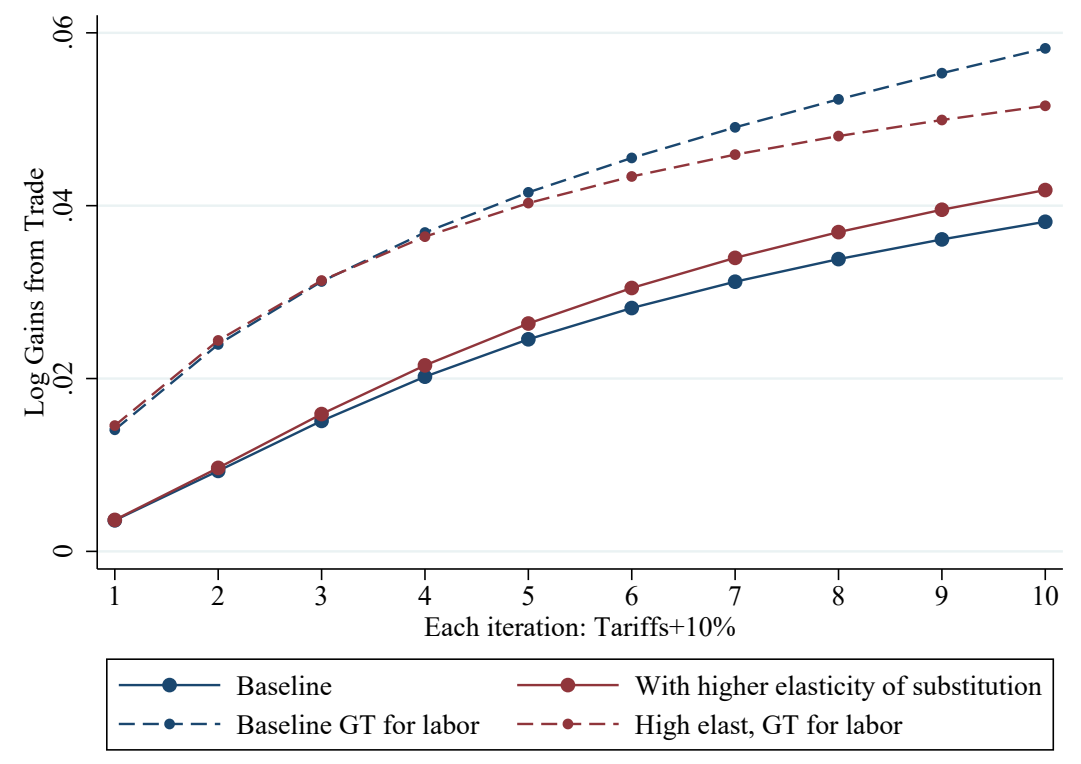

Figure 11: Gains from trade - increasing tariffs by $10 \%$ at each iteration 
Export taxes Simulating autarky starting from an imperfectly-competitive equilibrium with export taxes or optimal markups (on international markets) turns out to be very simple, with only minimal changes relative to the baseline counterfactual simulation. The main adjustment is to recalibrate the share of income related to labor and natural resources, now accounting for a non-zero share of profits or tax revenues.

In this counterfactual, we assume that each country (for each commodity) charges the optimal export tax, equal to the inverse of the import demand elasticity. For each commodity and country, we obtain a model-based estimate of the import demand elasticity by simulating a $1 \%$ increase in country level production costs for that commodity, and we use this estimate to calibrate the initial share of profits or tax revenues in the initial equilibrium. ${ }^{26}$

Interestingly, simulations starting from an equilibrium with distortions yield even larger gains from trade relative to when we start from a competitive equilibrium. The increment (in log gains) is equal to 0.1 on average, ranging from 0.02 to 0.2 for almost all countries. ${ }^{27}$ The calibrated gains are even larger because, conditional on observed trade flows, the initial equilibrium features additional sources of revenues and larger differences in productivity and endowments in resources.

\subsection{Reliance on critical suppliers}

As shown in Fact 9, the production of commodities is highly specialized across a few key exporters. This reliance on a few suppliers would lead to high costs associated with barriers to trade with such suppliers. We conduct a set of counterfactuals to illustrate the interdependence of nations and the critical role of the top exporter of any given commodity.

To illustrate and quantify the role of critical suppliers, we simulate a counterfactual equilibrium for each commodity where we shut down trade with the top exporter of that commodity, and examine the effect on commodity prices for other countries. There are two main channels through which these embargos influence prices. First, holding factor prices and production costs $\widehat{C}_{i g}$ constant, cutting trade from a source country leads to a higher price index $\widehat{P}_{i g}-$ this effect is highest for the largest exporter. Second, shutting down trade with any given exporter forces to increase production of that commodity in other source countries. Given the low price elasticity of supply facing commodities, this can potentially lead to large increases in producer prices and costs $\widehat{C}_{i g}-$ in the model, this is due to hiring additional workers at a low marginal product of labor.

We provide the results of these counterfactuals in Figure 12, where we plot the distribution of $\log \widehat{P}_{i g}$ and $\log \widehat{C}_{i g}$ across countries $i$ and commodities $g$ after excluding from world trade the main exporter of that commodity (e.g. Chile for copper, Indonesia for tin). We also provide it separately for each type of commodity (agriculture, fuels and minerals) in Appendix Figure 34. These figures

26. A good approximation of the import demand elasticity is: $-\theta_{g}-1+\left(\theta_{g}+1-\eta\right)\left(\sum_{n \neq i} X_{n i g} \lambda_{n i g}\right) /\left(\sum_{n \neq i} X_{n i g}\right)$. 27. Individual country results are plotted in Figure 33 in Appendix. 

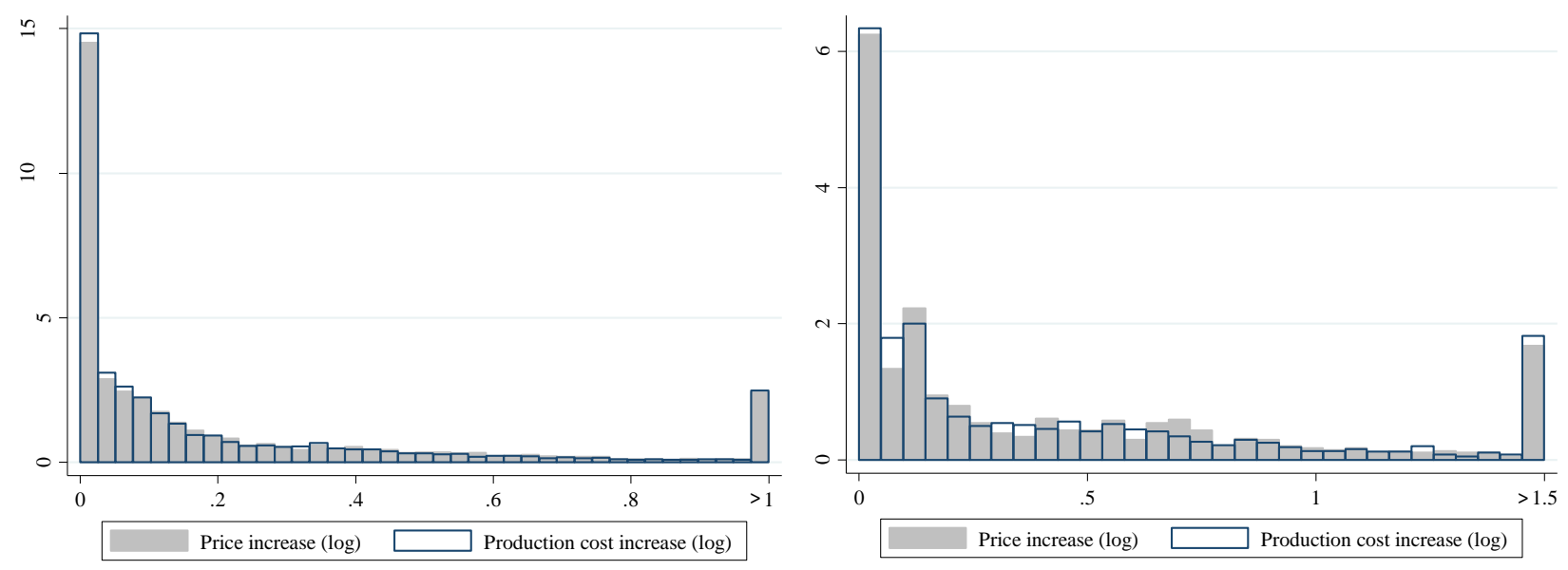

Figure 12: Shutting down trade with the top exporter: effect on prices and production costs (simulation for each commodity at a time; left: all cases; right: when top exporter is China)

indicate significantly large increases in prices in all cases. The more muted effects on fuel prices indicate the smaller share of the top exporter in the world supply of fuels. A large part of the price increase corresponds to the cost of having to produce more, as shown in Figure 12 where the distribution of $\log \widehat{C}_{i g}$ (hollow bars with blue contours) is close to the one for $\log \widehat{P}_{i g}$.

China as a critical supplier. China is the top exporter for fifteen commodities listed in Table 8. As a large exporter, a Chinese export embargo of those commodities leads to large effects on prices and production costs. The distribution of those price and cost shocks across importing countries for these commodities is shown in the right panel of Figure 12. It is skewed to the right: the median (in $\log$ ) is 0.17 for prices ( 0.16 for costs) and the 90 th percentile equals 1.27 ( 1.31 for costs).

In Table 8, we show in particular the counterfactual effect on prices for these commodities in the US. The largest impact would be for rare earth minerals. In recent experience, price increases of rare earth minerals of 525\% (1.83 log increase) between the period of 2009-2011 associated with a partial Chinese export embargo on rare earth minerals are similar to our predicted price increase. On the contrary, for iron, the simulated effect on US prices is limited to a $10 \%$ increase.

Table 8: Log US price increase from shutting down commodity production in China

\begin{tabular}{lc|lc|lc}
\hline \hline Commodity & Price Increase & Commodity & Price Increase & Commodity & Price Increase \\
\hline Rare Earths & 2.074 & Magnesium & 0.986 & Talc & 0.315 \\
Bismuth & 2.055 & Barytes, strontium & 0.885 & Cotton & 0.276 \\
Antimony & 1.384 & Manganese & 0.715 & Arsenic & 0.155 \\
Alliums & 1.289 & Graphite & 0.699 & Tungsten & 0.133 \\
Peanuts & 1.089 & Cement & 0.497 & Iron & 0.104 \\
\hline
\end{tabular}




\section{Concluding remarks}

In this paper, we emphasize the importance of commodities in international trade and demonstrate that upon consideration of the specific characteristics of primary commodity markets, such as low elasticities of demand and supply and a high dispersion of production, the gains from trade can greatly exceed those implied by standard models.

To arrive at these conclusions, an important step is to compile a new dataset containing information on trade, production, prices and demand for commodities at a disaggregated level. Using this dataset, we document that commodity production and trade tends to be highly concentrated within a few producers, and additionally, that export revenues of many countries are concentrated in a few commodities. We conduct a comprehensive meta-analysis to highlight the low price elasticity of demand and supply of commodities, while we also note that trade elasticities for commodities appear to be generally similar to those for manufacturing goods. Given these facts, it is less surprising that commodities play a crucial role in trade.

We develop a tractable model that can account for such features, which is easily compared to standard trade models. It is amenable to calibration and can be used to simulate various counterfactual policy changes; we provide such counterfactual simulations to highlight the role of commodities and natural resources under both small and large changes in trade costs and tariffs, and illustrate the mechanisms behind our results. In many cases, the welfare gains from trade depend largely on suppliers who account for the bulk of world commodity production; we find that shutting down trade with the top exporter for many commodities leads to large increases in commodity prices for downstream producers.

Overall, our results suggest that although primary commodities have a modest share in world trade, commodities are crucial inputs to many production processes, and thus have critical importance to international trade policy and welfare. The decline of the share of primary commodities in world trade must be considered against the large decreases in tariffs and transportation costs over the past seventy years, and the resulting large increase in trade volume relative to GDP. Increasing barriers to trade would lead to a resurgence of the share of primary commodities in total costs and larger welfare losses.

Some questions remain unanswered as to the potential magnitudes of the gains of trade. An open and policy-relevant question remains as to whether technological innovation and substitution patterns would yield long-run demand and supply responses that could mitigate some of these potentially large long-term losses associated with trade cost increases. Most demand and supply response estimates focus on short to medium-run responses, and reliable estimates of long-run elasticities are scarce. Further research in this area would be particularly relevant to better quantify the benefits from international trade and the impact of trade policy reforms. 


\section{References}

Acemoglu, D. 2002. "Technical change, inequality, and the labor market.” Journal of Economic Literature 40 (1).

Aguiar, A., R. McDougall, and B. Narayanan. 2012. Global Trade, Assistance, and Production: The GTAP 8 Data Base. Center for Global Trade Analysis, Purdue University.

Alexander, P. 2017. "Vertical Specialization and Gains from Trade.” Bank of Canada Working Paper.

Anderson, J. 1979. "A theoretical foundation for the gravity equation.” The American Economic Review 69 (1). 2011. “The gravity model.” Annual Review of Economics 3 (1): 133-160.

Antràs, P., D. Chor, T. Fally, and R. Hillberry. 2012. "Measuring the upstreamness of production and trade flows." The American Economic Review 102 (3): 412-416.

Antràs, P., and A. de Gortari. 2017. "On the Geography of Global Value Chains." NBER WP No. 23456.

Arkolakis, C., A. Costinot, and A. Rodríguez-Clare. 2012. "New trade models, same old gains?" The American Economic Review 102 (1): 94-130.

Arkolakis, C., N. Ramondo, A. Rodríguez-Clare, and S. Yeaple. 2013. "Innovation and production in the global economy." National Bureau of Economic Research WP No. 18972.

Autor, D. H., L. F. Katz, and A. B. Krueger. 1998. "Computing inequality: have computers changed the labor market?" The Quarterly Journal of Economics 113 (4): 1169-1213.

Barry, J. J., G. R. Matos, and W. D. Menzie. 2015. A Crosswalk of Mineral Commodity End Uses and North American Industry Classification System (NAICS) codes. US Geological Survey.

Blattman, C., J. Hwang, and J. G. Williamson. 2007. "Winners and losers in the commodity lottery: The impact of terms of trade growth and volatility in the Periphery 1870-1939." Journal of Development Economics 82 (1).

Blaum, J., C. Lelarge, and M. Peters. 2015. "The gains from input trade with heterogeneous importers." National Bureau of Economic Research WP No. 21504.

British Geological Survey. 2015. "World Mineral Statistics Archive."

Broda, C., and D. E. Weinstein. 2006. "Globalization and the Gains From Variety." The Quarterly Journal of Economics 121 (2): 541-585.

Brooks, D. B. 1966. Low-grade and nonconventional sources of manganese. Resources for the Future; distributed by Johns Hopkins Press, Baltimore.

Burstein, A., E. Morales, and J. Vogel. 2018. "Changes in between-group inequality: computers, occupations, and international trade." American Economic Journal: Macroeconomics.

Cafiero, C., E. Bobenrieth, J. Bobenrieth, and B. D. Wright. 2011. "The empirical relevance of the competitive storage model." Journal of Econometrics 162 (1): 44-54.

Caliendo, L., and F. Parro. 2015. "Estimates of the Trade and Welfare Effects of NAFTA." The Review of Economic Studies 82 (1): 1-44.

Caron, J., and T. Fally. 2017. "Per Capita Income, Consumption Baskets, and CO2 Emissions." Working Paper.

Carter, C., G. Rausser, and A. Smith. 2011. "Commodity booms and busts." Annual Review of Resource Economics.

Cashin, P., H. Liang, and C. J. McDermott. 2000. "How persistent are shocks to world commodity prices?" IMF Staff Papers 47 (2): 177-217.

Chaney, T. 2008. "Distorted gravity: the intensive and extensive margins of international trade." The American Economic Review 98 (4): 1707-1721. 
Charles River Associates. 1971. "An economic analysis of the aluminum industry."

Cohen, D., T. Fally, and S. Villemot. 2006. "In Favour of a Fund to Stabilize Commodity Exporters' Income." CEPR Discussion Papers.

Comin, D. A., D. Lashkari, and M. Mestieri. 2015. "Structural change with long-run income and price effects." National Bureau of Economic Research WP No. 21595.

Commodities Team of the Research Department, IMF. 2017. "IMF Primary Commodity Prices."

Corden, W. M., and J. P. Neary. 1982. "Booming Sector and De-Industrialisation in a Small Open Economy." The Economic Journal 92 (368): 825-848.

Costinot, A., and D. Donaldson. 2012. "Ricardo's theory of comparative advantage: Old idea, new evidence." American Economic Review 102 (3): 453-58.

2016. "How large are the gains from economic integration? Theory and evidence from US agriculture, 18801997.” National Bureau of Economic Research WP No. 22946.

Costinot, A., D. Donaldson, and I. Komunjer. 2011. "What goods do countries trade? A quantitative exploration of Ricardo's ideas.” The Review of Economic Studies 79 (2): 581-608.

Costinot, A., D. Donaldson, and C. Smith. 2016. "Evolving comparative advantage and the impact of climate change in agricultural markets: Evidence from 1.7 million fields around the world." Journal of Political Economy 124 (1).

Costinot, A., and A. Rodríguez-Clare. 2014. "Trade Theory with Numbers: Quantifying the Consequences of Globalization.” Handbook of International Economics: 197-261.

Dekle, R., J. Eaton, and S. Kortum. 2008. "Global rebalancing with gravity: Measuring the burden of adjustment." IMF Staff Papers 55 (3): 511-540.

Donaldson, D. 2018. "Railroads of the Raj: Estimating the impact of transportation infrastructure." American Economic Review 108 (4-5): 899-934.

Drechsel, T., and S. Tenreyro. 2017. "Commodity Booms and Busts in Emerging Economies." NBER WP No. 23716.

Easterly, W., and A. Reshef. 2010. "African export successes: Surprises, stylized facts, and explanations." National Bureau of Economic Research WP No. 16597.

Eaton, J., and S. Kortum. 2002. “Technology, geography, and trade.” Econometrica 70 (5): 1741-1779.

Fally, T. 2012. "Production Staging: Measurement and Facts." Working Paper.

2015. "Structural gravity and fixed effects." Journal of International Economics 97 (1): 76-85.

Fally, T., and R. Hillberry. 2018. “A Coasian Model of International Production Chains.” Journal of International Economics, forthcoming.

FAO/IIASA. 2010. "Global Agro-ecological Zones (GAEZ v3.0).” FAO, Rome, Italy and IIASA, Laxenburg, Austria.

Farrokhi, F. 2018. "Global Sourcing in Oil Markets."

Feenstra, R. C. 1994. "New product varieties and the measurement of international prices." The American Economic Review: $157-177$.

Food and Agriculture Organization of the United Nations. 2017. "FAOSTAT statistics database."

Galle, S., A. Rodríguez-Clare, and M. Yi. 2017. "Slicing the pie: Quantifying the aggregate and distributional effects of trade." National Bureau of Economic Research WP No. 23737.

Gaulier, G., and S. Zignago. 2010. "BACI: International Trade Database at the Product-Level. The 1994-2007 Version." CEPII WP No. 2010-23 (). 
Gilbert, C. L. 2010. "How to understand high food prices.” Journal of Agricultural Economics 61 (2).

Gouel, C., and D. Laborde. 2017. "The crucial role of international trade in adaptation to climate change."

Hanson, G. H., N. Lind, and M.-A. Muendler. 2015. “The dynamics of comparative advantage.” NBER WP No. 21753.

Heerman, K. E., and I. M. Sheldon. 2018. "Gravity and Comparative Advantage: Estimation of Trade Elasticities for the Agricultural Sector.” National Bureau of Economic Research WP No. 24772.

Hertel, T. W., J. M. Horridge, and K. R. Pearson. 1992. "Mending the family tree: a reconciliation of the linearization and levels schools of AGE modelling." Economic Modelling 9 (4): 385-407.

Jacks, D. S., K. H. O’Rourke, and J. G. Williamson. 2011. “Commodity Price Volatility and World Market Integration since 1700." The Review of Economics and Statistics 93 (3): 800-813.

Jacks, D. S., and M. Stuermer. 2018. "What drives commodity price booms and busts?” Energy Economics.

Kelly, T., and G. Matos. 2014. "Historical statistics for mineral and material commodities in the United States (2016 version)." U.S. Geological Survey Data Series 140.

Krugman, P. 1980. "Scale economies, product differentiation, and the pattern of trade." The American Economic Review 70 (5): 950-959.

Ossa, R. 2015. “Why trade matters after all.” Journal of International Economics 97 (2): 266-277.

Poelhekke, S., and F. van der Ploeg. 2013. "Do Natural Resources Attract Nonresource FDI?" The Review of Economics and Statistics 95 (3): 1047-1065.

Radetzki, M., and L. Wårell. 2017. A Handbook of Primary Commodities in the Global Economy. Cambridge University Press.

Roberts, M. J., and W. Schlenker. 2013. "Identifying supply and demand elasticities of agricultural commodities: Implications for the US ethanol mandate." The American Economic Review 103 (6): 2265-2295.

Sachs, J. D., and A. M. Warner. 1999. “The big push, natural resource booms and growth.” Journal of Development Economics 59 (1): 43-76.

Scott, P. 2014. "Dynamic Discrete Choice Estimation of Agricultural Land Use.” Working Paper.

Simonovska, I., and M. E. Waugh. 2014. "The elasticity of trade: Estimates and evidence.” Journal of international Economics 92 (1): 34-50.

Sotelo, S. 2017. "Domestic trade frictions and agriculture." In Understanding Productivity Growth in Agriculture. University of Chicago Press.

The World Bank. 2017. "World Development Indicators (1960-2016).”

Tiffin, R., K. Balcombe, M. Salois, and A. Kehlbacher. 2011. Estimating food and drink elasticities. University of Reading.

Toews, G., and P.-L. Vézina. 2017. "Resource discoveries and FDI bonanzas: An illustration from Mozambique.”

Tombe, T. 2015. "The missing food problem: Trade, agriculture, and international productivity differences.” American Economic Journal: Macroeconomics 7 (3): 226-258.

U.S. Energy Information Association. 2017. "Natural Gas Prices."

Williams, J. C., and B. D. Wright. 2005. Storage and commodity markets. Cambridge university press.

World Bank Group. 2017. "World Bank Commodity Price Data (Pink Sheets), Global Economic Monitor Commodities."

Wright, B. D. 2011. “The economics of grain price volatility.” Applied Economic Perspectives and Policy 33 (1). 